\title{
Assessing Socioeconomic Risks of Extreme Weather Events: Lessons from El Niño-Related Road Damages in Peru
}

Jean-Marc Montaud ( $\square$ jean-marc.montaud@univ-pau.fr )

Universite de Pau et des Pays de l'Adour https://orcid.org/0000-0002-7616-7697

Jorge Davalos

Universidad del Pacifico

Nicolas Pecastaing

Universidad del Pacifico

\section{Research Article}

Keywords: Extreme weather events, Risk assessment, Computable General Equilibrium, Peru

Posted Date: July 9th, 2021

DOI: https://doi.org/10.21203/rs.3.rs-610245/v1

License: (c) This work is licensed under a Creative Commons Attribution 4.0 International License.

Read Full License 


\title{
Assessing Socioeconomic Risks of Extreme Weather Events: Lessons from El Niño-related Road Damages in Peru
}

\author{
Jean-Marc Montaud (Corresponding author) \\ Universite de Pau et des Pays de l'Adour, E2S UPPA, CNRS, TREE, Bayonne, France \\ E-mail: jean-marc.montaud@univ-pau.fr \\ Postal address: Collège EEI, 8 Allée des Platanes, 64100, Bayonne France \\ Tel: +33660459887
}

\section{Jorge Dávalos}

Universidad del Pacífico, Centro de Investigación de la Universidad del Pacifico (CIUP), Lima, Perú, Partnership for Economic Policy

E-mail: je.davalosc@up.edu.pe

\author{
Nicolas Pécastaing \\ Universidad del Pacífico, Centro de Investigación de la Universidad del Pacifico (CIUP), Lima, Perú \\ E-mail: n.pecastaing@up.edu.pe
}

\begin{abstract}
Periodically, heavy rainfall associated with extreme El Niño events severely damage the Peruvian road-network. This study aims to assess the socio-economic effects of these non-frequent but recurrent climate shocks. For this purpose, we build a Computable General Equilibrium model that addresses the consequences of El Niño-related damages through an increase in interregional transportation costs and a negative externality effect on activities' output, which has been estimated beforehand using a firm database. For designing simulation scenarios over a tenyear period where extreme El Niño events occurs at random as observed in the past in Peru, we model the occurrence of these events as a stochastic process with a VAR representation based on historical climatic data. Within this framework, we first show that such events constitute a significant one-off disaster risk for the country, threatening shifts of $-2.8 \%$ in GDP and $+1.9 \%$ in poverty rates with an annual probability $p=1.4 \%$. We further show that they also present a longer-term risk, leading to average annual deviations from normal trend by $-0.8 \%$ in GDP and $+0.4 \%$ in poverty rate with a probability $p=12.6 \%$ over a ten-year period. However, we finally show that Peru might reduce these risks in constructing more disaster-resilient road infrastructure.
\end{abstract}

Keywords: Extreme weather events; Risk assessment; Computable General Equilibrium; Peru 


\section{Introduction}

El Niño events present the most important adverse climatic threat to Peru, regularly causing major disasters in the country. For instance, in 1982-83, 1997-98 and 2017, heavy rainfalls associated with particularly severe events produced extensive landslides and flash flooding throughout the country, leading to widespread destructions of homes and agricultural productions as well as major disruptions of critical infrastructure such as water and sanitation systems and road networks. The direct economic losses of these damages are regularly reported. In 1998 and 2017, they were for instance estimated to 3.5 billion USD (6.3\% of GDP) and 9 billion USD (4.2\% of GDP), respectively [1,2]. However, their adverse higher-order cascading consequences for Peruvian economy and society remain surprisingly poorly investigated.

In this context, the main objectives of this study are to quantify the indirect socio-economic costs of extreme El Niño events in Peru and to assess the risk that such infrequent but recurrent shocks present to this country. Testing evaluation methods appears indeed to be of primary importance for assessing how these extreme weather events can be an impediment to Peruvian development and household welfare, and might help to design effective preventive strategies. However, one key insight of the economic literature is that assessing the effects of such natural disasters is challenging (for comprehensive reviews, see e.g. Rose [3]; Okuyama [4]; Kelly [5]; Meyer et al. [6]; Jahn [7] or Botzen et al. [8]). On the one hand, the many interacting factors determining their ultimate indirect consequences in the short run as well as in the longer run necessitate dealing with complexity. On the other hand, the hazardous nature of such events and their low probabilities of occurrence also imply to deal with uncertainty.

For addressing both these issues, some methodological choices were therefore made upstream to our analysis. First, as many studies stress that addressing all impacts of natural disaster appears challenging (or even illusory) methodologically, we chose to focus on one main specific direct impacts of extreme El Niño events in Peru, which is their damages to road 
infrastructure. The Peruvian economy is indeed highly dependent on road transportation, which is the dominant mode for transporting people and products across the country. However, its road network relies on a few critical links, which are particularly vulnerable to heavy rainfall given the specific topography of the country. As an illustration, the 1997-98 El Niño event damaged $8.2 \%$ of national primary roads, while the 2017 event damaged $7.2 \%$ [1,2]. Second, we chose to use a Computable General Equilibrium (CGE) model for our analysis. In economic literature, a growing number of studies apply CGE modelling for a variety of extreme events and a variety of effects at the global, national, and local levels (see e.g. Rose and Liao [9]; Pauw et al. [10]; Koks et al. [11]; Mac Donald et al. [12]). One of its main benefits is indeed to convert the abstract Walrassian theory into an applicable simulation apparatus and therefore to represent a multi-market economy as a system of interdependent components in a fully coherent analytical micro-macro general equilibrium framework. With economic agents responding to relative price signals on both the supply and demand sides of the economy, it thus promises to shed light on a wide range of complex indirect effects of extreme events-related damages that would be ignored with other methodologies, such as empirical approaches (see e.g., RodriguezOreggia [13]; Felbermayr and Gröschl [14]; Baez et al. [15]; Salazar et al. [16]) or input-output models (see e.g. Hallegate [17] ; Okuyama and Santos [18]). Third, in order to gain further in complexity, we chose to use a multiregional (MR) framework for our CGE model, rather than the standard economy-wide framework. Considering spatial dimensions appeared to be of primary importance for providing a deeper understanding of the effects of extreme El Niño event-related road damages in Peru. On the one side, this country has a structural "lagging regions" problem [19,20], with an important gap between its coastal regions and its other regions, that should be included in our general equilibrium analysis. On the other side, as observed in the past, this country is affected by two types of El Niño events with distinct regional distributions of damages [21]. Global events (like for instance in 1982-83 and 1997- 
98), whose effects are worldwide, affect mainly the northern coast and the northern Andean and Amazonian regions. Coastal events (like for instance in 2017), whose effects are more localised in Peru (and Ecuador), affect also the northern coast and, above all, the region of Lima, which is the economic core of the country. Fourth, we retain a dynamic framework for our MR-CGE model. A first benefit of this choice is to allow us to consider not only the one-off disaster effects of El Niño events for their year of occurrence but also their lasting effects, or even their cumulative effects if they occur several times over the period of simulation. A second benefit is that it also allows us to adopt a risk-assessment perspective for our analysis by including uncertainty features regarding the hazardous occurrence of El Niño events. Fifth, as CGE modelling results are only relevant at the representative household group level, we also linked our CGE model with a household survey-based microeconomic module that we use to capture the effects of road destructions in term of poverty.

Beyond the specific study case of Peru, the contribution of our analysis to the extant economic literature about the economic effects of extreme weather events appears finally twofold. The first contribution concerns the choices we made for considering how El Niñorelated physical road damages transfer to cascading indirect flow losses across the Peruvian economy in our general equilibrium modelling framework. As is commonly done in other CGE studies with a transport focus (see e.g. Shahrokhi Shahraki and Bachmann [22] for a review), we firstly consider rising transportation costs with associated ripple effects through increased prices for producers and consumers. However, and more originally, we secondly consider a negative externality effect on the productivity of Peruvian activities. Since the seminal works of Aschauer [23] or Munnel [24], there is indeed a broad consensus among economists that a proper functioning of core infrastructure such as road-network is closely related to overall economic performance, specifically in developing countries like Peru (see e.g. Romp and de Haan [25]; Straub [26] for surveys). To our knowledge, this potential adverse indirect effect of 
extreme events, which is by nature non-marketed and not related to inter-sectoral relationships, has never been included in other CGE studies. This is we seek to do in this work. However, as this effect plays a critical role in our simulations, we also chose to prior econometrically estimate its magnitude in Peru with a firm database at national level, instead of making arbitrary assumptions.

The second contribution of this study concerns the ways we define relevant scenarios to be simulated with the MR-CGE model and that are representative of the weather conditions usually experienced by Peru over a ten-year period. Following recent studies in climatic literature [27,28], we model the dynamic of occurrence of extreme El Niño events in the country as a stochastic process with a vector autoregressive econometric model based on historical climatic data. Then, applying a non-parametric bootstrap procedure, we generate numerous replications of ten-year series where Global and/or Coastal events occur at random.

This article is structured as follows. Section 2 details the main features of the dynamic MRCGE model. Section 3 explains the main hypotheses and procedures adopted in designing the scenarios for simulations and Section 4 presents the results of these simulations. Section 5 finally addresses the opportunity for Peru to implement some preventive actions to reduce El Niño event-related risks.

\section{Modelling framework}

\subsection{Dynamic MR-CGE model}

Our CGE model features six regions for the Peruvian economy, one government agent, six groups of households (one per region), and nine non-transport activities plus one transport activity in each of the six regions (equations and variables are presented in supplementary material). 
Its within-period specifications rely on standard assumptions of CGE analysis for a developing country (see e.g. Decaluwé et al. [29]). On the supply side, each producer of a sector $j$ in a region $r$ maximises its profit by combining skilled and unskilled labour with fixed capital with a standard Cobb-Douglas technology. On the income side, each agent receives factor revenues and transfer income from other agents. On the demand side, households' consumptions follows a linear expenditure system derived from maximisation behaviours of Stone-Geary utility functions. Government's consumption is supposed to be exogenous in each region. Intermediate consumptions are driven by fixed technical coefficients with Leontief specifications and demands for investment purposes are derived from nominal investments and distributed among commodities and regions in fixed shares. On the market side, each good can be sold in its region, in another region, or overseas. Constant Elasticity of Transformation functions govern the rates at which the proportions of these sales change according to the relative price variations, which are determined endogenously. Domestic goods of a specific region are assumed imperfectly substitutable with imported goods and those of other regions, given Armington specifications. Their prices are determined endogenously to equilibrate supply and demand in each regional market. For labour markets, the skilled and unskilled overall labour forces are fixed nationally, and workers flow freely across activities and regions with wage rate determined endogenously. In the capital market, we assume that all regions generate savings that go into a national pool to be allocated to investments at a national level. Finally, the nominal exchange rate is the numeraire for the economy and the current account balance is fixed.

The between-period specifications of the model are in a dynamic recursive framework. They mainly concern the accumulation of capital in each activity at time $t$, which depends on an exogenous depreciation rate and on the volume of new capital installed in time $t-1$. In the public sector, the latter is exogenous. In private activities, it derives from an investment function 
and allocated in a putty-clay fashion across sectors and regions in accordance with returns to investment.

On these bases, for a given time $t$, the vector of prices and wages for which demand equals supply in all markets simultaneously defines the general equilibrium of the economy. Accordingly, the model can be used to generate time paths for endogenous variables over a given time-period by numerically simulating successive equilibriums under different scenarios of shocks. This period has been set relatively short (ten years) for excluding significant structural changes in the Peruvian economy and thus maintain the consistency of the model initial calibration. Given the purposes of this study, the first variables of interest for these 10year simulations are the levels of road network infrastructure in each region $r$ at time $t\left(\operatorname{Road}_{r, t}\right)$. In the spirit of Aschauer [23], they are supposed to determine the total factor productivity of each private activity $\mathrm{j}$ in each region $\mathrm{r}$. In other CGE studies, this effect is often modelled through an indirect link between public expenditure on road infrastructure and productivity [30,31]. As shown in equations (1) and (2), we rather chose a direct link, modelled in a Hicks's neutral manner, through the variable $\theta_{j, r, t}^{R O A D}$ in the production function and an externality parameter $\varepsilon_{j, r}^{\text {road }}$. In the simulations, as shown in equation (3), we will thus suppose that $\operatorname{Road}_{r, t}$ can be negatively affected $\left(\overline{\Delta r o a d_{r}}\right)$ by an extreme El Niño event for a time of occurrence $t$ $\left(\overline{N_{\imath} 0_{r, t}}\right)$. After an event, we will also suppose that exogenous specific public investments for

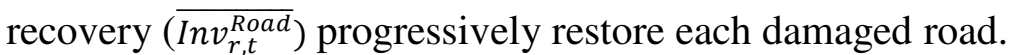

(1) $V A_{j, r, t}=\theta_{j, r, t}^{R O A D} \cdot F(L, K)$

(2) $\theta_{j, r, t}^{R O A D}=\left[\frac{\operatorname{Road}_{t}}{\operatorname{Road}_{t-1}}\right]^{\varepsilon_{j, r}^{\text {road }}}$

(3) $\operatorname{Road}_{r, t}=\left(1-\overline{N_{\imath} \tilde{n} o_{r, t}} \cdot \overline{\Delta \operatorname{road}_{r}}\right) \cdot \operatorname{Road}_{r, t-1}$

$\overline{N l n ̃ o_{r, t}}=1$ if $t$ is a year of occurence or 0 if not. $\left.\overline{\Delta r o a d}, \in\right] 0,1\left[\overline{\text { Inv } v_{r, t}^{\text {Rad }}}\right.$ are further included in (3) over the recovery period 
The second variables of interest for the simulations are the levels of transportation costs at time $t$ for each product $i$ that travels from its region of origin $r$ to another region $r^{\prime}$. These costs depend in part on the prices of the industry of each region that produces the transport service, which are determined endogenously in the model. However, they are also driven by interregional technical coefficients $\left(\operatorname{transp}_{i, r^{\prime}, r, t}^{R}\right.$ and $\left.\operatorname{transp}_{i, r^{\prime}, r, t}^{X}\right)$, which are determined by the distance (or travel time) between producers and buyers. As shown in equations (4) and (5), we will suppose that the occurrence of an extreme El Niño event increases these coefficients for domestic products and exported products $\left(\overline{\Delta t r_{l, r^{\prime}, r}^{R}}\right.$ and $\left.\overline{\Delta t r_{l, r}^{X}}\right)$ because of damaged road networks.

(4) $\operatorname{transp}_{i, r^{\prime}, r, t+1}^{R}=\operatorname{transp}_{i, r, r, t, t o}^{R}\left(1+\overline{N l \tilde{n} o_{r, t}} \cdot \overline{\Delta t r_{l, r^{\prime}, r}^{R}}\right)$

(5) $\operatorname{transp}_{i, r, t+1}^{X}=\operatorname{transp}_{i, r, t o}^{X} \cdot\left(1+\overline{N\left(\tilde{n} o_{r, t}\right.} \cdot \overline{\Delta t r_{l, r}^{X}}\right)$

$N$ iñ $o_{r, t}=1$ if $t$ is a year of occurence or 0 if not. $\Delta t t_{i, r}^{R}$ and $\Delta t t_{i, r}^{X}>0$

\subsection{Data for model initialization and calibration}

We obtain the initial general equilibrium of the economy from the last Social Accounting Matrix (SAM) available in Peru [32] that we earlier disaggregated between six regions. The Peruvian Institute of Statistics identifies three main regions in Peru under topographic, economic, and demographic criteria: the Costa (the Pacific coast area), the Selva (the Amazonian area), and the Sierra (the Andean area). However, in order to better consider the specific regional effects of extreme El Niño events on road networks, we further divided the Costa and Sierra territories between two transversal regions (North and South), and finally, given the weight of the region of Lima in the Peruvian economy, we also chose to isolate this specific area from the Costa. Table 1 indicates some descriptive statistics of each region based on this multi-regional SAM.

TABLE 1 
Most parameters of the MR-CGE model are calibrated with this SAM. Where this was not possible, we obtain the parameters from other models for Peru. However, as externality parameters $\left(\varepsilon_{j, r}^{\text {road }}\right)$ play a critical role in the model, we chose to prior econometrically estimate their magnitudes. For these purposes, we use the Peruvian Encuesta Economica Annual (EEA), which consists of the data for almost 60,000 firms for 2004-2015. Consistent with the MRCGE model, we adopt a primal function approach by considering road networks as additional input in production functions. In line with Montaud et al. [33], we thus assume that value added at time $t$ for each firm $i$ pertaining to each activity $j$ in each region $r\left(v a_{i, j, r, t}\right)$ follows a CobbDouglas specification:

(6) $y_{i, j, r, t}=e^{a_{j} u r b_{i, r, t}} \cdot\left[\frac{\operatorname{Road}_{r, t+1}}{\operatorname{Road}_{r, t}}\right]^{\varepsilon_{j, r}^{\text {Road }}} . \tilde{l}_{i, j, r, t}^{\alpha_{j}}$ With $y_{i, j, r, t}=v a_{i, j, r, t} / k_{i, j, r, t}$ and $\tilde{l}_{i, j, r, t}=l_{i, j, r, t} / k_{i, j, r, t}$ where $l_{i, j, r, t}$ and $k_{i, j, r, t}$ are respectively labour and capital (in monetary units), assumed to be exogenously determined by the wages and rental rates on labour and capital markets. $u r b_{i, r, t}$ is an urbanisation rate parameter (function of the population density of the region) at the firm's headquarters, which is included for consideration of the potential productivity gains from urban agglomeration [34]. Similar to Calderón et al. [35], $\operatorname{Road}_{r, t}$ is the total length of the paved regional roads (in $\mathrm{km}$ ) relative to the agricultural land (in square $\mathrm{km}$ ). Regarding potential endogeneity concerns, we assume that the $i$-th firm's value added has a negligible effect on road infrastructure in our multilevel setup, and can be thus considered exogenous. For the cost of capital, we use the average interest rate in foreign currency for the Peruvian financial market as a natural instrument. For labour, given the time series nature of data, a second instrumental exploits autocorrelation information implied in a lagged indicator $\left(l_{i, j, r r t-1}\right)$ collected by the EEA survey along with the current year information. Table 2 presents the final estimate for $\varepsilon_{j, r}^{R o a d}$. The $F$-statistics provide strong evidence against the weakness of the instruments, and the externality parameters tend to exhibit significant results, ranging from 0.11 to 0.38 in the Costa 
and Lima regions, although it is non-significant for the Construction, Energy-Water, and Manufacture sectors. In the Sierra and Selva regions, they are all significant (except for the Energy-Water sector), ranging from 0.09 to 0.27 .

\section{TABLE 2}

Finally, we also use the 2019-National household survey (ENAHO) in order to feed a microeconomic module linked with the MR-CGE model with a top-down approach [36]. In this perspective, consistent with the Stone-Geary utility function used for maximisation behaviours in the MR-CGE model, we assume Cobb-Douglas preferences for consumers in each region and thus derive individual equivalent consumption that are used to calculate poverty rates for each time $t$.

\section{Stochastic simulation scenarios}

\subsection{Nature of extreme El Niño events in Peru}

From a climatic perspective, an El Niño phenomenon corresponds to a warm phase of the El Niño Southern Oscillation (ENSO), that is, an unusual increase in both sea surface temperatures (SST) in the central and/or eastern equatorial regions of the Pacific Ocean and in sea level atmospheric pressures in its western regions [37]. Different indicators define the conditions of occurrence and the intensity of this phenomenon. The most popular is perhaps the Oceanic Niño Index (ONI) of the US National Oceanic and Atmospheric Administration (NOAA). The latter takes a three-month mean SST anomaly of $0.5^{\circ} \mathrm{C}$ (with respect to the $1981-$ 2010 period) in the Niño.3.4 Pacific region (see Map 1) as constituting an indication for stating that an event is under way. On these bases, each event is classified as Weak (with a $0.5^{\circ} \mathrm{C}$ to 
$0.9^{\circ} \mathrm{C} \mathrm{SST}$ anomaly), Moderate $\left(1.0^{\circ} \mathrm{C}\right.$ to $\left.1.4^{\circ} \mathrm{C}\right)$, Strong $\left(1.5^{\circ} \mathrm{C}\right.$ to $\left.1.9^{\circ} \mathrm{C}\right)$, or Very Strong $\left(\geq 2.0^{\circ} \mathrm{C}\right)$.

\section{MAP 1}

When it occurs, this warm phase of ENSO is able to change weather patterns worldwide. In the particular case of Peru, depending on its duration and intensity, it can lead to more or less intense rainfall. For instance, the 1982-83 Very Strong event was certainly the most negative shock experienced by the country. Starting during the agricultural period for 17 months, it contributed to a reduction of $-7 \%$ in real GDP [38]. More recently, the consequences of the Very Strong 1997-98 event were estimated at $-4.5 \%$ of real GDP [39]. However, things are a bit more complicated for Peru as, in addition to these Global events, another type of phenomena also drastically affects the country: the Coastal El Niño. This more localised event (unique to the Peruvian and Ecuadorian coastline) is characterised by a warming of SST along the Peruvian coasts but cooler conditions in other regions [21]. Since 2012, the Peruvian El Niño study agency (ENFEN) has used its own index (ICEN) in order to monitor such phenomena. It is based on SST anomalies exceeding $+0.4{ }^{\circ} \mathrm{C}$ for at least three months in the easternmost Niño.1+2 Pacific region. Coastal El Niño events are often classified as weaker than Global events upon climatic criteria, mainly because of their shorter duration. However, they can produce comparable negative consequences in Peru based upon economic criteria. INDECI [2] estimated for instance that the 2017 event contributed to a $-1.6 \%$ change of real GDP. Figure 1 summarises the occurrence of each of these different extreme El Niño events experienced by Peru since 1950.

\section{FIGURE 1}




\subsection{Extreme El Niño event-related shock intensities}

For considering the intensity of the shocks induced by each type of event in the scenarios for simulations with the MR-CGE model, we started by evaluating their respective physical damages on Peruvian road networks $\left(\overline{\left(\text { road }_{r}\right.}\right)$. At the national level, the latter is close to 24500 km length, of which $70 \%$ is in asphalt and $30 \%$ is in more basic pavement [40]. As shown in Table 3 and Map 2, it is relatively unequally distributed over regions and is mainly organised around a few main critical corridors and two structural axes (the Pan-American Highway sitting along the coastline and the Carretera Central connecting Lima with central Peru). As it is common for extreme events with low frequency of occurrence, time series data of the impacts of El Niño events on Peruvian roads are not available. In this context, we had no choice but to use an ad hoc approach by referring to the last most destructive events experienced by the country, in 1997-98 for a Global event and 2017 for a Coastal event. In 2017, 19.1\% of roads were destroyed in the Costa Norte and $21.4 \%$ in the region of Lima [2]. The other regions suffered less damage, with $6.3 \%$ of roads destroyed in the Sierra Norte, $4 \%$ in the Sierra Sur, $3.4 \%$ in the Costa Sur, and no significant damages in the Selva region. In 1997-98, major damages were observed in Costa Norte, Sierra Norte, and Selva $(24.2 \%, 11.2 \%$, and $11.0 \%$ of roads destroyed, respectively) and minor destructions in Lima, Costa Sur, and Sierra Sur (6.3\%, $3.9 \%$, and $1.6 \%$, respectively, [1]).

TABLE 3

\section{MAP 2}

Once these damages have been located across regions, we secondly evaluated their associated increases of transportation costs across the country $\left(\overline{\Delta t r_{l, r^{\prime}, r}^{R}}\right.$ and $\left.\overline{\Delta t r_{l, r}^{X}}\right)$. For this purpose, using the index of link criticality proposed by Rozenberg et al. [41], we approximated the number of additional kilometres needed for transporting products after damage from an 
event. By comparing these additional kilometres to the total distance between regions, we therefore deduce the additional transport costs (in percent) associated with each road destruction. At this point, it should be stressed that we only assumed additional costs when a region experienced a major destruction rate (higher than 10\%), and that the destination of exported products for all regions is always the region of Lima, given its weight (90\%) in total exports for Peru.

Finally, our scenarios also include the levels of investments needed for road networks recovery after an event $\left(\overline{\operatorname{Inv} v_{r, t}^{\text {Road }}}\right)$. At this stage, we used the costs of reconstruction provided by the Peruvian Ministry of Transport and Communications [42]. These costs differ according to the location of damages (given the topography of each region) and the nature of pavement. As indicated by Peruvian authorities after the 2017 event, we moreover considered that damaged roads can be restored to their original design in four years. Accordingly, we will thus suppose in the simulations that, after a year of occurrence, an event has lasting (but progressively decreasing) effects on roads levels and transportations costs until the recovery process completes. Table 4 summarises the main hypotheses that we finally retained in our scenarios.

\section{TABLE 4}

\subsection{Extreme El Niño events' likely frequencies over a 10-year period}

Given the hazardous nature of extreme El Niño events in Peru, the scenarios also consider the probabilities of occurrence of events over the 10-year period of simulation. In the climatic literature, physically-based models are the primary tool for evaluating these probabilities. Nevertheless, although their ability to simulate El Niño-related dynamics at the global scale has improved markedly in recent years, they still exhibit errors in predictions regarding the amplitude, period, irregularity, or spatial patterns of the phenomenon [37]. In this context, 
alternative parsimonious approaches consist in using statistical estimates derived from past weather pattern analyses [27, 28, 43, 44]. In line with these works, we thus modelled the likely annual occurrence of extreme El Niño events $\left(\overline{N_{l} \tilde{n} o_{r, t}}\right)$ over ten years from the stochastic process that governs the SST anomalies. For this purpose, using NOAA data for SST over the 18702019 period in the four El Niño Pacific regions, we modelled the SST anomalies' crossdependence between the four regions as well as the self-dependence (autocorrelation) within regions by a VAR representation.

As a first step, we tested whether SST anomalies' series are stationary by means of an augmented Dickey-Fuller test with drift, where the optimal number of lags is chosen in such a way that the auxiliary regression residuals are white noise. Results in Table 5 show that the unit-root (null) hypothesis is rejected for the four series and that the stationarity can be thus accepted.

\section{TABLE 5}

As a second step, we therefore estimated a stationary VAR model of the four series in levels where the number of lags is chosen according to a Bayesian Information Criteria:

(7) $y_{t}=\sum_{j=1}^{J} B_{j} y_{t-j}+\varepsilon_{t}$

where, $y_{t}$ is a $4 \times 1$ column vector of the monthly SST anomalies across the four regions at time $t$. $B_{j}$ is a $4 \times 4$ coefficient matrix that represents the cross-dependence and autoregressive behaviour of $y_{t}$ with respect to the $j$-th lag. The autoregressive order is given by $J$. From this model, as described by Fresoli et al. [45], we implemented a non-parametric bootstrap procedure for ten years, which delivers a multi-array of 100 thousand replications of time series. Every $i$-th replication is noted $Y_{i}^{*}$, a matrix with 4 columns (the four Pacific regions) and 120 rows (the number of months over the 10-year period). 
As a third step, and in order to identify objective criteria allowing the identification of either 1997-98 Global or 2017 Coastal events in the 100 thousand time series, we trained a simple classification algorithm (linear discriminant analysis; LDA) from the four SST (smoothed) anomalies historical data. Once trained, we applied these estimated LDA classification rules to all simulated (smoothed) anomalies obtained in the previous step. The confusion matrix obtained from this LDA shows that our classifier exhibits an average accuracy of 0.996 . Finally, we transformed the 100 thousand simulated time series $Y_{i}^{*}$ from a monthly to a yearly basis to obtain $N_{i}^{*}$, a matrix with 4 columns and 10 rows. Whenever a Coastal or a Global event overlaps over two consecutive years, we chose to assign it to the year of the first month of occurrence.

Figure 2 presents the final estimate of the annual probabilities of observing El Niño events in Peru over a 10-year period, comparable to the last 1997-98 and 2017 extreme events experienced by this country. On average, this annual probability is $P_{c}^{t}=1.16 \%$ for a Coastal event and $P_{g}^{t}=0.19 \%$ for a Global event. Table 6 further presents the joint distribution of the probabilities of observing these extreme events during the period. These results serve as a basis for scenarios to be simulated with the MR-CGE model. The first one, which is the most likely over the period (with a probability $P_{B A U}=87.41 \%$ ), corresponds to the Business As Usual scenario where no event occurs $\left(\mathrm{SC}_{\mathrm{BAU}}\right)$. The other consider stochastic occurrences of events. The scenarios with only one Coastal event $\left(\mathrm{SC}_{1.0}\right)$ or only one Global event $\left(\mathrm{SC}_{0.1}\right)$ over the period exhibit probabilities of $10.03 \%$ and $1.66 \%$, respectively. The scenarios with two Coastal events $\left(\mathrm{SC}_{2.0}\right)$, one Coastal event and one Global event ( $\left.\mathrm{SC}_{1.1}\right)$, two Global events $\left(\mathrm{SC}_{0.2}\right)$, and, finally, three events, either Coastal or Global $\left(\mathrm{SC}_{N=3}\right)$, exhibit much lower probability $(0.64 \%$, $0.19 \% 0.03 \%$, and $0.04 \%$, respectively).

\section{FIGURE 2}




\section{TABLE 6}

\section{Simulation results and discussion}

Following the standard procedure in dynamic CGE modelling, we first simulate the $\mathrm{SC}_{\mathrm{BAU}}$ scenario over the 10 -year period by updating various constants and exogenous variables from one year to the next, using the annual population growth rate (which is close to $1.1 \%$ ). Second, we identify among the 100 thousand time series $\left(N_{i}^{*}\right)$ those that correspond to each of the six 'El Niño scenarios' and feed the MR-CGE model for comparing their simulation outcomes with those of the $\mathrm{SC}_{\mathrm{BAU}}$. The weighted mean of these results, where the proper weight of each sequence is defined by the probability of observing it within a scenario, yields the average likely effects of extreme El Niño events for this scenario. Within this framework, our simulations should thus be understood as counterfactual experiments, which identify ceteris paribus the differences in the evolution of the Peruvian economic system that can be attributed to the occurrence of extreme El Niño events over a 10-year period. Table 7 presents some selected results of these simulations.

\section{TABLE 7}

\subsection{Disaster effects of events for a year of occurrence}

The first three columns in Table 6 isolate the mean indirect one-off socio-economic costs of roads damage that are observed for an El Niño event in Peru for a year of occurrence among all scenarios. The first column does not make distinction between events. Its results show that, on average, when an event occurs (either Global or Coastal with an annual probability $P_{n}^{t}=$ $1.35 \%$ ), it causes an annual deviation from BAU in the national GDP of $-2.79 \%$ along with an 
increase in prices of $+8.47 \%$. In this deteriorating economic environment, household welfare also degrades sharply, with significant decreases of real income per capita $(-3.21 \%)$ as well as degraded poverty rates $(+1.86 \%)$. Coastal events result in stronger impacts than Global events because of the largest share of activities affected by road network disruptions. When occurring (with an annual probability $P_{c}^{t}=1.16 \%$ ), the national GDP on average fall by $-2.95 \%$, and prices increase by $+9.03 \%$ and the poverty rate by $+1.96 \%$. For a Global event $\left(P_{g}^{t}=0.19 \%\right)$ these shifts are $-1.79 \%,+5.05 \%$, and $+1.23 \%$ respectively.

These disaster effects of events are relatively evenly spread over regions. The Costa Norte, which is particularly physically impacted by both Coastal and Global events, logically appears as one of the most affected region in terms of GDP $(-3.99 \%$ and $-3.51 \%$, respectively), prices $(+10.07 \%$ and $+6.43 \%$, respectively), household income $(-5.40 \%$ and $-6.36 \%$, respectively), and poverty $(+3.46 \%$ and $+4.11 \%$, respectively). For its part, when such an event occurs, the Lima region, for which only Coastal Niño events induce heavy physical road damages, experiences a one-off fall of $-3.26 \%$ in its GDP, an increase of $+8.39 \%$ in prices, a $-3.91 \%$ decrease in household income, and a $+1.77 \%$ absolute increase in the poverty rate. Although impacts on roads are less for the region for a Global event, its preponderant weight in the Peruvian economy ( $52 \%$ of national GDP) and its various links with other regions however lead to relatively strong one-off indirect effects on its GDP $(-1.57 \%)$, prices $(+4.53 \%)$, and household welfare $(-1.14 \%$ for income and $+0.66 \%$ for poverty rate). Finally, the case of the Selva region deserves attention. The latter is directly physically impacted by Global events, with likely strong indirect effects on its GDP $(-2.31 \%)$, prices $(+6.59 \%)$, household income $(-3.30 \%)$, and poverty $(+2.15 \%)$. In the case of Coastal events, it does not experience direct road disruptions. However, this remote area, which weights little in the national GDP (only $5.1 \%$ ), but which depends strongly on other regions (notably Lima) for supplies and exports, is 
indirectly affected with a decrease in GDP of $-2.98 \%$, an increase in prices of $+9.89 \%$, a degradation of household welfare of $-1.75 \%$ for income and $+1.30 \%$ for poverty rate.

Figure 3 shows how the one-off indirect effects of each event extend over the four years after the disaster. Over this period, road networks are gradually scaled up but remain damaged, with persistent adverse effects in terms of transportation costs and productivity externalities. Over the same time, public investments for recovery also produce ceteris paribus their own macroeconomic effects. First, by increasing the demand for the Construction activities that produce the capital goods required for restoring roads, they generate multiplier effects and therefore upward pressure on demand and prices on product markets. Second, given the savings-investment constraint driving the capital market's equilibrium, they also generate crowding-out effects for other investments for non-recovery purposes. All these combined effects finally contribute to a progressive decrease of the adverse consequences of events until the recovery process is completed.

\section{FIGURE 3}

\subsection{Average effects of events over the 10 -year period}

These lasting effects of events, as well as their possible multiple occurrences over the period, are considered in a longer-term risk-assessment perspective in the next columns in Table 7. The $\mathrm{SC}_{\mathrm{N}}$ scenario corresponds to the occurrence of at least one extreme event (either Global or Coastal) over the period. The probability of such scenario is $P_{N}=12.59 \%$. Results show that it leads to average annual deviations from the $\mathrm{SC}_{\mathrm{BAU}}$ trend over 10 years of $-0.75 \%$ in GDP,$+2.19 \%$ in prices, $-0.75 \%$ in households income per capita along with $+0.43 \%$ increases in the poverty rate. Here again, the expected effects of events are evenly spread over regions 
even if the Costa Norte is still the most affected region in terms of GDP $(-0.94 \%)$, prices $(+2.46 \%)$, household income $(-1.33 \%)$, and poverty $(+0.93 \%)$.

Results also show how an increasing frequency of events threatens long run macroeconomic performance and household welfare (see also Figure 4). In the most favourable case, if one event occurs over the 10-year period ( $\mathrm{SC}_{\mathrm{N}=1}$ with $\left.P_{1}=11.66 \%\right)$, it causes average annual deviations from the $\mathrm{SC}_{\mathrm{BAU}}$ trend of $-0.71 \%$ in $\mathrm{GDP},+2.07 \%$ in prices, $-0.71 \%$ in household income per capita, and $+0.41 \%$ in poverty rate. These shifts are respectively $-0.75 \%$, $+2.20 \%,-0.75 \%$ and $+0.43 \%$, in the case of one Coastal event $\left(\mathrm{SC}_{1.0}\right.$ with $\left.P_{1.0}=10.03 \%\right)$ and $-0.46 \%,+1.29 \%,-0.45 \%$ and $+0.26 \%$, in the case of one Global event $\left(\mathrm{SC}_{0.1}\right.$ with $\left.P_{0.1}=1.66 \%\right)$. In the most unfavourable (however unlikely) scenario $\left(\mathrm{SC}_{\mathrm{N}=3}\right.$ with $\left.P_{3}=0.04 \%\right)$, if three events occur over the 10 -year period they cause average annual deviations of $-1.74 \%$ in GDP, $5.16 \%$ in prices, $-1.77 \%$ in income per capita and $+1.11 \%$ in the poverty rate.

\section{FIGURE 4}

\section{Exploring options for reducing the extreme El Niño event risk in Peru}

In previous simulations, the socio-economic risk associated with extreme El Niño events depended on the occurrence of hazards on the one hand and on the level of vulnerability of regional road networks on the other. If reducing hazard occurrence is not an option, preparing appropriate preventive plans that allow the improvement of the road network's resilience to event impacts might be of great interest. Currently, such a perspective is not really considered by Peruvian authorities as, for past events, planning and preparation were only characterised by 'emergency' short-term ex-ante measures conducted in the months immediately prior to events' predicted onset or by ex-post interventions for recovery [46]. Yet, there seems to be some room 
to manoeuvre in constructing more disaster-resilient road infrastructure and to accommodate the heavy rainfall associated with these events. As shown by the Road Quality Indicator [47], the Peruvian road network is indeed in a particularly poor condition, only ranking 111th of 141 countries in 2019. In this context, as suggested by the World Bank [40], a first action could consist in progressively upgrading the most fragile primary roads (that is those destroyed during the 1997-98 and 2017 events) to flood- and landslide-proof status. Adding tunnels, raising the level of roads, and strengthening structures and drainage capacity could help to achieve this. A second action could consist in increasing the redundancy of these critical links by upgrading existing alternative second-best routes to primary paved roads so as to be equivalent to firstbest roads. In a first approach, we consider these options to be implemented at national level over the 10-year period. However, in a second, more pragmatic approach, we consider that only the two regions most affected by El Niño events, that is Costa Norte and Lima, can benefit from such investments. The respective costs of these plans are taken from the World Bank [40].

Table 8 presents selected results of the simulations of previous stochastic scenarios when Peruvian government implemented such preventive plans. They show that all strategies might appear worthwhile in buffering the expected disaster effects of events as well as their negative average longer-term effects over the 10 -year period, without however fully eliminating the risks. In our general equilibrium framework, they also show that targeting the most impacted regions should be preferred to nation-wide plans with strong crowding-out effects on other investments for non-infrastructural purposes. Similarly, given its positive externality effects on activity productivity, extending the current primary road network by upgrading extant secondbest roads should be preferred to upgrading the most fragile primary regional roads.

\section{TABLE 8}

To gain further insight into these results, Table 9 finally presents two cost-effectiveness indicators that allow us to address the critical question of how much each million USD annually 
invested over 10 years actually minimises the consequences of extreme El Niño events on national GDP and poverty rate. Regarding these criteria, results show that investments might generate positive average net returns in terms of growth and poverty, if at least one event occurs over the period $\left(P_{N}=12.59 \%\right)$. However, when considering the very likely possibility that no event occurs, the only profitable strategy would be to upgrade the extant second-best roads in the Costa Norte and Lima.

\section{TABLE 9}

\section{Conclusion}

Using a multiregional dynamic CGE model and a historical-based bootstrap procedure for designing relevant scenarios of the occurrence of extreme El Niño events in Peru over a 10year period, this study shows that their related road damages constitute not only a significant disaster risk for this country, but also a longer-term risk threatening its economic performance and household welfare. However, it also shows that some profitable options might be implemented for managing this risk, such as, for instance, increasing the redundancy of the most fragile critical roads in the most affected regions. If these findings offer a valuable indication of extreme El Niño event risk levels for Peru and a useful guideline for conducting preventive actions, some caution should however be exercised when interpreting their absolute magnitude, as some caveats must be considered in our methodology.

First, this study does not fully address the challenge of complexity of assessing extreme El Niño event indirect effects on the Peruvian economy and therefore underestimates their real related risk. By focusing solely on road damages, it ignores all other effects that clearly alter economic performances and household welfare. For instance, the impacts on the agricultural 
sector could also be considered, given the numerous forward and backward linkages of this sector with other sectors and its dominant influence on the incomes of the poorest populations. However, such inclusion is not straightforward, as it would require better adapting the modelling framework to accommodate the very specific conditions prevailing under a disaster situation. In this spirit, one promising line of research could be to include temporary disequilibria assumptions in the MR-CGE model arising from supply bottlenecks, shorter-run behaviour for economic agents, or restrictions on the movements of labour.

Second, this study does not also fully address the challenge of uncertainty in evaluating extreme El Niño event effects and/or occurrence. On the one side, regarding the valuation of events' respective damages to Peruvian roads, we had no choice but to refer to the 1997-98 and 2017 events. However, as suggested by French and Mechler [46], some variability could be expected between the impacts of events of a same type. On this front, the United Nations Office for Disaster Risk Reduction has recently started to develop international time-series data (including for road damages) that could help assist in better addressing risks in the future. On the other side, regarding the frequencies of events in Peru over ten years, the potential influence of a warming climate on ENSO variability is a source of uncertainty that we did not consider in our analysis. Although there is still no clear consensus regarding an intensification of El Niño events in the 21 st century, some studies however confirm a possible risk of more frequent stronger episodes, especially for Coastal events [48]. However, by imposing a constant volatility of SST anomalies in the VAR modelling, our historical-based bootstrap procedure cannot take into account this risk. An alternative approach, where SST anomalies dispersion is modelled by means of a conditional heteroskedasticity framework, could certainly usefully be explored in order to better consider this potential recent (and future) influence of climate change. 


\section{Author Declarations}

Funding: Not applicable

Conflicts of interest/Competing interests: the authors declare that they have no conflict of interest

Availability of data and material: data are available at the end of the manuscript

Code availability: codes are available at the end of the manuscript

\section{Authors' contributions:}

J.M Montaud: CGE modelling and redaction of the paper

J. Davalos: Econometric modelling

N. Pecastaing: Data collections

\section{References}

1. INDECI (1998). Consolidado de danos producidos por fenómeno el Nino 1997-1998. Direcciones regionales de defensa civil, Lima, Perú.

2. INDECI (2018). Boletín Estadístico Virtual de la Gestión Reactiva. Dirección de Políticas, Planes y Evaluación, $N^{o} 09$ - Ano 5 - Jul 2018. Lima, Perú.

3. Rose A. (2004). Economic Principles, Issues, and Research Priorities in Hazard Loss Estimation. In: Okuyama Y., Chang S.E. (eds) Modeling Spatial and Economic Impacts of Disasters. Advances in Spatial Science. Springer, Berlin, Heidelberg. https://doi.org/10.1007/978-3-540-24787-6_2

4. Okuyama, Y. (2007). Economic Modelling for Disaster Impact Analysis: Past, Present, and Future. Economic Systems Research, 19(2), 115-124. doi:10.1080/09535310701328435

5. Kelly, S. (2015). Estimating economic loss from cascading infrastructure failure: a perspective on modelling interdependency. Infrastruct. Complex 2, 7. https://doi.org/10.1186/s40551-015-0010-y

6. Meyer, V., Becker, N., Markantonis, V., Schwarze, R., van den Bergh, J. C. J. M., Bouwer, L. M., ... Viavattene, C. (2013). Review article: Assessing the costs of natural hazards - state of the art and knowledge gaps. Natural Hazards and Earth System Sciences, 13(5), 1351-1373. doi:10.5194/nhess-13-1351-2013

7. Jahn, M. (2015). Economics of extreme weather events: Terminology and regional impact models. Weather and Climate Extremes, 10, 29-39. doi:10.1016/j.wace.2015.08.005

8. Botzen, W. J. W., Deschenes, O., \& Sanders, M. (2019). The Economic Impacts of Natural Disasters: A Review of Models and Empirical Studies. Review of Environmental Economics and Policy, 13(2), 167-188. doi:10.1093/reep/rez004. 
9. Rose, A., \& Liao, S.-Y. (2005). Modeling Regional Economic Resilience to Disasters: A Computable General Equilibrium Analysis of Water Service Disruptions. Journal of Regional Science, 45(1), 75-112. doi:10.1111/j.0022-4146.2005.00365.x

10. Pauw, K., Thurlow, J., Bachu, M., \& Van Seventer, D. E. (2012). The economic costs of extreme weather events: a hydrometeorological CGE analysis for Malawi. Environment and Development Economics, 16(2), 177-198. doi:10.1017/s1355770x10000471

11. Koks, E. E., Carrera, L., Jonkeren, O., Aerts, J. C. J. H., Husby, T. G., Thissen, M., Standardi, G., and Mysiak, J. (2016). Regional disaster impact analysis: comparing input-output and computable general equilibrium models, Nat. Hazards Earth Syst. Sci., 16 (8), 1911-1924. doi:10.5194/nhess16-1911-2016

12. McDonald, G.W., Cronin, S.J., Kim, J., Smith, N.J., Murray, C., \& Procter, J. (2017). Computable general equilibrium modelling of economic impacts from volcanic event scenarios at regional and national scale, Mt. Taranaki, New Zealand. Bulletin of Volcanology, 79, 1-18.

13. Rodriguez-Oreggia, E., De La Fuente, A., De La Torre, R., \& Moreno, H., A.(2013) Natural Disasters, Human Development and Poverty at the Municipal Level in Mexico, The Journal of Development Studies, 49:3, 442-455, DOI: 10.1080/00220388.2012.700398

14. Felbermayr, G. \& Gröschl, J.K. (2014). "Naturally Negative: The Growth Effects of Natural Disasters," Journal of Development Economics 111:92-106. doi:10.1016/j.jdeveco.2014.07.004.

15. Baez, J. E., Lucchetti, L., Genoni, M., E., \& Salazar M. (2017) Gone with the Storm: Rainfall Shocks and Household Wellbeing in Guatemala, The Journal of Development Studies, 53:8, 12531271, DOI: $10.1080 / 00220388.2016 .1224853$

16. Salazar C., Hailemariam, A., \& Fisker, P (2019). Weather Shocks and Spatial Market Efficiency: Evidence from Mozambique, The Journal of Development Studies, 55:9, 1967-1982, DOI: $10.1080 / 00220388.2018 .1528352$

17. Hallegatte, S. (2008). An Adaptive Regional Input-Output Model and its Application to the Assessment of the Economic Cost of Katrina. Risk Analysis, 28(3), 779-799. doi:10.1111/j.15396924.2008.01046.x

18. Okuyama, Y., \& Santos, J. R. (2014). Disaster Impact and Input-Output Analysis. Economic Systems Research, 26(1), 1-12. doi:10.1080/09535314.2013.871505

19. Thurlow J, Morley S, Nin-Pratt A, (2009). "Lagging regions and development strategies: The case of Peru". IFPRI discussion papers 898, International Food Policy Research Institute (IFPRI).

20. Seminario B., Zegarra M.A., Palomino L. (2020) Peruvian Regional Inequality: 1847-2017. In: Tirado-Fabregat D.A., Badia-Miró M., Willebald H. (eds) Time and Space. Palgrave Studies in Economic History. Palgrave Macmillan, Cham. http://doi-org-

443.webvpn.fjmu.edu.cn/10.1007/978-3-030-47553-6_10

21. Takahashi, K. (2017). Fenómeno El Niño: “Global” vs “Costero”. Boletín Técnico El Niño - IGP, 4 (4), 4-7. 
22. Shahrokhi Shahraki, H., \& Bachmann, C. (2018). Designing computable general equilibrium models for transportation applications. Transport Reviews, 38(6), 737-764. doi:10.1080/01441647.2018.1426651

23. Aschauer, D. A. (1989). Is public expenditure productive? Journal of Monetary Economics, 23(2), 177-200. doi:10.1016/0304-3932(89)90047-0

24. Munnell, A.H. (1992). Policy Watch: Infrastructure Investment and Economic Growth. Journal of Economic Perspectives, 6(4), 189-198. doi:10.1257/jep.6.4.189

25. Romp, W., \& de Haan, J. (2007). Public Capital and Economic Growth: A Critical Survey. Perspektiven Der Wirtschaftspolitik, 8(S1), 6-52. doi:10.1111/j.1468-2516.2007.00242.x

26. Straub, S. (2011). Infrastructure and Development: A Critical Appraisal of the Macro-level Literature. Journal of Development Studies, 47(5), 683-708. doi:10.1080/00220388.2010.509785

27. Chapman, D., Cane, M. A., Henderson, N., Lee, D. E., \& Chen, C. (2015). A Vector Autoregressive ENSO Prediction Model. Journal of Climate, 28(21), 8511-8520. doi:10.1175/jclid-15-0306.1

28. Lee, D. E., Chapman, D., Henderson, N., Chen, C., \& Cane, M. A. (2016). Multilevel vector autoregressive prediction of sea surface temperature in the North Tropical Atlantic Ocean and the Caribbean Sea. Climate Dynamics, 47(1-2), 95-106. doi:10.1007/s00382-015-2825-5

29. Decaluwé, B., Lemelin, A., Robichaud, V., \& Maisonnave, H. (2013). PEP-1-t Standard Model: Single-country, Recursive Dynamic Version, Poverty and Economic Policy Network, Université Laval, Québec. Retrieved from www.pep-net.org

30. Boccanfuso, D., Joanis, M., Richard, P., \& Savard, L. (2014). A comparative analysis of funding schemes for public infrastructure spending in Quebec. Applied Economics, 46(22), 2653-2664. doi:10.1080/00036846.2014.909576

31. Mosa, A. A., Grethe, H., \& Siddig, K. (2020). Macroeconomic effects of improving road transport infrastructure in Ethiopia: A computable general equilibrium model analysis. Journal of Economics and International Finance, 12(3), 105-119. doi: 10.5897/JEIF2020.1048

32. Ministry of Production (2016). Modelo Económico de Equilibrio General Computable para simular impactos de Políticas de Desarrollo Productivo. Dirección de Estudios Económicos de Mype e Industria (DEMI), Lima, Perú.

33. Montaud, J.-M., Dávalos, J., \& Pécastaing, N. (2020). Potential effects of scaling-up infrastructure in Peru: a general equilibrium model-based analysis. Applied Economics, 52(27), 2895-2912. doi:10.1080/00036846.2019.1696940

34. Melo, P. C., Graham, D. J., \& Noland, R. B. (2009). A meta-analysis of estimates of urban agglomeration economies. Regional Science and Urban Economics, 39(3), 332-342. doi:10.1016/j.regsciurbeco.2008.12.002 
35. Calderón, C., Moral-Benito, E., \& Servén, L. (2014). Is infrastructure Capital Productive? A Dynamic Heterogeneous Approach. Journal of Applied Econometrics, 30(2), 177-198. doi:10.1002/jae.2373

36. Tiberti, L., Cicowiez, M., \& Cockburn, J. (2018). A Top-Down with Behaviour (TDB) Microsimulation Toolkit for Distributive Analysis. International Journal of Microsimulation, 11(2), $191-213$.

37. Timmermann, A., An, S., Kug, J. et al. (2018). El Niño-Southern Oscillation complexity. Nature 559, 535-545 (2018). doi:10.1038/s41586-018-0252-6

38. CEPAL (1983). Los desastres naturales en Bolivia, Ecuador y Perú. E/CEPAL/G.1274. Santiago, Chile.

39. CAF - Andean Development Corporation, (2000). El Fenomeno El Niño 1997-1998: Memoria, retos y Soluciones. CAF, Volumen V. Lima. CAF.

40. World Bank (2016). Improving the Reliability of Peru's Road Network. Washington, DC: World Bank. Available at: https://cdn.www.gob.pe/uploads/document/file/31326/21953_Improving_the_Reliability_Peru_Ro ad_Network.pdf20180706-19116-1s68wlo.pdf.

41. Rozenberg, J., Briceno-Garmendia, C., Lu, X., Bonzanigo, L., Moroz, H. (2017). Improving the Resilience of Peru's Road Network to Climate Events. World Bank, Washington, DC. Retrieved from https://openknowledge.worldbank.org/handle/10986/26355

42. Ministry of Transport and Communications (2016). Programa de Inversiones 2011-2016 - Gestión estrategica - Corredores logísticos. Oficina general de planeamiento y presupuesto. Lima, Perú.

43. Barnston, A. G., Tippett, M. K., L'Heureux, M. L., Li, S., \& DeWitt, D. G. (2012). Skill of RealTime Seasonal ENSO Model Predictions during 2002-11: Is Our Capability Increasing? Bulletin of the American Meteorological Society, 93(5), 631-651. doi:10.1175/bams-d-11-00111.1

44. Chen, M., Kumar, A., \& Wang, W. (2015). A study of the predictability of sea surface temperature over the tropics. Climate Dynamics, 44(7-8), 1767-1776. doi:10.1007/s00382-014-2187-4

45. Fresoli, D., Ruiz, E., \& Pascual, L. (2015). Bootstrap multi-step forecasts of non-Gaussian VAR models. International Journal of Forecasting, 31(3), 834-848. doi:10.1016/j.ijforecast.2014.04.001

46. French, A. and Mechler, R. (2017). Managing El Niño Risks Under Uncertainty in Peru: Learning from the past for a more disaster-resilient future. Laxenburg, Austria: International Institute for Applied Systems Analysis.

47. World Economic Forum (2019). Global Competitiveness Report 2019. The World Economic Forum. Available at: www.weforum.org/gcr

48. Cai, W., G. Wang, B. Dewitte, L. Wu, A. Santoso, K. Takahashi, Y. Yang, A. Carréric, M. J. Mcphaden (2018). Increased variability of eastern Pacific El Niño under greenhouse warming. Nature, 564(7735), 201-206. doi:10.1038/s41586-018-0776-9 
LIST OF TABLES

Table 1 - Weight of Peruvian regions in total national (in \%)

\begin{tabular}{lcccccc}
\hline & Lima & $\begin{array}{c}\text { Costa } \\
\text { Norte }\end{array}$ & $\begin{array}{c}\text { Costa } \\
\text { Sur }\end{array}$ & $\begin{array}{c}\text { Sierra } \\
\text { Norte }\end{array}$ & $\begin{array}{c}\text { Sierra } \\
\text { Sur }\end{array}$ & Selva \\
\hline Share of population & 35.7 & 17.2 & 4.6 & 15.8 & 17.5 & 9.2 \\
Contribution to national GDP & 52.4 & 12.0 & 7.0 & 10.2 & 13.4 & 5.1 \\
Contribution to national sectoral GDP & & & & & & \\
$\quad$ Agro-industry & 15.8 & 21.6 & 10.0 & 17.4 & 21.0 & 14.2 \\
$\quad$ Fishing & 17.7 & 47.6 & 13.8 & 8.0 & 7.5 & 5.4 \\
$\quad$ Oil-Mining & 7.0 & 10.9 & 13.4 & 30.2 & 32.1 & 6.5 \\
$\quad$ Energy-water & 57.2 & 7.3 & 4.1 & 11.4 & 17.1 & 2.8 \\
$\quad$ Manufacture & 60.9 & 11.2 & 10.5 & 5.3 & 9.0 & 3.1 \\
$\quad$ Construction & 40.8 & 12.4 & 8.8 & 12.4 & 20.7 & 5.0 \\
$\quad$ Trade-transport & 54.1 & 14.1 & 4.5 & 8.8 & 12.0 & 6.5 \\
$\quad$ Other services & 64.1 & 10.5 & 3.3 & 7.7 & 10.0 & 4.4 \\
$\quad$ Public administration & 49.9 & 12.3 & 4.2 & 12.8 & 13.6 & 7.3 \\
\hline
\end{tabular}

Source: Own calculations from the regional Social Accounting Matrix for Peru 
Table 2 - Estimates of road network externality effects on private activities output in the different regions of Peru

\begin{tabular}{|c|c|c|c|c|c|c|c|c|}
\hline & $\begin{array}{l}\text { Agro- } \\
\text { industry }\end{array}$ & Fishing & $\begin{array}{l}\text { Oil - } \\
\text { Mining }^{(2)}\end{array}$ & $\begin{array}{l}\text { Energy- } \\
\text { Water }\end{array}$ & Manufacture & Construction & $\begin{array}{l}\text { Trade- } \\
\text { Transport }\end{array}$ & $\begin{array}{l}\text { Other } \\
\text { services }\end{array}$ \\
\hline \multicolumn{9}{|c|}{ Costa Norte, Costa Sur, Lima } \\
\hline$\Delta \log (\operatorname{Road})$ & $0.19 * * *$ & $0.11^{* * *}$ & $0.38 * *$ & -0.13 & -0.05 & -0.01 & $0.33 * * *$ & $0.20 * * *$ \\
\hline $\log (\mathrm{L} / \mathrm{K})$ & $0.54 * * *$ & $0.51 * * *$ & $0.19 * * *$ & $0.30 * * *$ & $0.61 * * *$ & $0.67 * * *$ & $0.64 * * *$ & $0.62 * * *$ \\
\hline $\begin{array}{l}\text { Urbanization } \\
\text { rate }\end{array}$ & $2.51 * * *$ & $1.58^{* * *}$ & $2.39 * * *$ & $3.45^{* * *}$ & $1.20 * * *$ & $3.23 * * *$ & $2.39 * * *$ & $3.17 * * *$ \\
\hline R-sq & 0.85 & 0.77 & 0.56 & 0.72 & 0.59 & 0.87 & 0.97 & 0.90 \\
\hline F-stat (IV) & 1148 & 498 & 69 & 120 & 4075 & 1399 & 19992 & 9144 \\
\hline Sample size & 721 & 585 & 208 & 164 & 9766 & 813 & 10646 & 5279 \\
\hline
\end{tabular}

\begin{tabular}{|c|c|c|c|c|c|c|c|c|}
\hline \multicolumn{9}{|c|}{ Sierra Norte, Sierra Sur, Selva } \\
\hline$\Delta \log (\mathrm{Road})$ & -0.01 & $0.27 * *$ & -- & -0.04 & $0.09^{* *}$ & $0.12^{*}$ & $0.18 * * *$ & $0.17 * * *$ \\
\hline $\log (\mathrm{L} / \mathrm{K})$ & $0.50^{* * * *}$ & $0.61 * * *$ & -- & $0.33 * * *$ & $0.59 * * *$ & $0.54 * * *$ & $0.71 * * *$ & $0.62 * * *$ \\
\hline $\begin{array}{l}\text { Urbanization } \\
\text { rate }\end{array}$ & $0.79 * * *$ & -0.68 & -- & 0.26 & $0.93 * * *$ & 0.17 & $-0.17 * * *$ & $0.45 * * *$ \\
\hline R-sq & 0.68 & 0.79 & -- & 0.68 & 0.75 & 0.75 & 0.85 & 0.84 \\
\hline F-stat (IV) & 110 & 109 & -- & 46 & 824 & 185 & 8101 & 1844 \\
\hline Sample size & 174 & 102 & -- & 78 & 993 & 241 & 5069 & 2330 \\
\hline
\end{tabular}

Source: Own calculations based on the Peruvian EEA survey 2004-2015

Notes: (1) Bootstrap standard errors clustered at the regional level $* \mathrm{p}<0.05$, **p $<0.01$, ***p $<0.001$; (2) No estimates for Oil-Mining in the Sierra Norte, Sierra Sur and Selva due to the very low degrees of freedom resulting from the few observations in the database 
Table 3 - Main characteristics of regional road networks in Peru

\begin{tabular}{|c|c|c|c|c|c|c|c|}
\hline & Lima & $\begin{array}{l}\text { Costa } \\
\text { Norte }\end{array}$ & $\begin{array}{l}\text { Costa } \\
\text { Sur }\end{array}$ & $\begin{array}{l}\text { Sierra } \\
\text { Norte }\end{array}$ & $\begin{array}{l}\text { Sierra } \\
\text { Sur }\end{array}$ & Selva & National \\
\hline $\begin{array}{l}\text { Total length of paved road } \\
\left.\text { network }^{(1)} \text { (in } \mathbf{k m}\right)\end{array}$ & 1492 & 3511 & 1960 & 7110 & 8065 & 2361 & 24500 \\
\hline Share of Primary roads & $88.9 \%$ & $84.7 \%$ & $88.5 \%$ & $91.1 \%$ & $78.1 \%$ & $87.4 \%$ & $85.2 \%$ \\
\hline Asphalt & $83.6 \%$ & $76.5 \%$ & $91.4 \%$ & $68.8 \%$ & $60.8 \%$ & $69.7 \%$ & $70.3 \%$ \\
\hline Basic & $17.4 \%$ & $23.5 \%$ & $8.6 \%$ & $31.2 \%$ & $39.2 \%$ & $30.3 \%$ & $29.7 \%$ \\
\hline Share of Secondary roads & $11.1 \%$ & $15.3 \%$ & $11.5 \%$ & $8.9 \%$ & $21.9 \%$ & $12.6 \%$ & $14.8 \%$ \\
\hline Share in national road network & $6.1 \%$ & $14.3 \%$ & $8.0 \%$ & $29.0 \%$ & $32.9 \%$ & $9.6 \%$ & $100 \%$ \\
\hline \multicolumn{8}{|l|}{$\begin{array}{l}\text { Average Annual Daily Traffic } \\
\text { (vehicles per day) }\end{array}$} \\
\hline $\mathrm{AADT}<400$ & $14.0 \%$ & $13.3 \%$ & $26.3 \%$ & $27.1 \%$ & $21.2 \%$ & $26.0 \%$ & $22.19 \%$ \\
\hline $400<\mathrm{AADT}<2000$ & $32.0 \%$ & $31.4 \%$ & $42.1 \%$ & $42.9 \%$ & $49.4 \%$ & $52.0 \%$ & $43.5 \%$ \\
\hline AADT > 2000 & $54.0 \%$ & $55.2 \%$ & $31-.6 \%$ & $29.9 \%$ & $29.5 \%$ & $22.0 \%$ & $34.2 \%$ \\
\hline
\end{tabular}

Source: Based on Ministry of Transport and Communications (2016)

Note: (1) Including total national and departmental paved roads 
Table 4 - Extreme EI Niño events-related shock intensities in simulation scenarios

a. Road networks damages and level of investments needed for recovery

\begin{tabular}{|c|c|c|c|c|c|c|c|}
\hline & Lima & $\begin{array}{l}\text { Costa } \\
\text { Norte }\end{array}$ & $\begin{array}{c}\text { Costa } \\
\text { Sur }\end{array}$ & $\begin{array}{l}\text { Sierra } \\
\text { Norte }\end{array}$ & $\begin{array}{c}\text { Sierra } \\
\text { Sur }\end{array}$ & Selva & National \\
\hline \multicolumn{8}{|c|}{$\begin{array}{l}\text { Damages in } \% \text { of total regional } \\
\text { paved network }\left(\Delta \operatorname{road}_{r}\right)\end{array}$} \\
\hline Coastal event & $-21,4$ & $-19,1$ & $-3,4$ & $-6,3$ & $-4,0$ & 0,0 & $-7,2$ \\
\hline Global event & $-6,3$ & $-24,2$ & $-3,9$ & $-11,2$ & $-1,6$ & $-11,0$ & $-8,2$ \\
\hline \multicolumn{8}{|c|}{$\operatorname{Recovery~costs}^{(1)}\left(\right.$ Inv $\left._{r, t}^{\text {Road }}\right)$} \\
\hline Coastal event & 85 & 166 & 21 & 89 & 102 & 0.25 & 463 \\
\hline Global event & 25 & 211 & 24 & 159 & 40 & 77 & 536 \\
\hline
\end{tabular}

\section{b - Increases of bilateral transport coefficients between regions (in \%)}

$$
\Delta t r_{i, r^{\prime}, r}^{R} \text { and } \Delta t r_{i, r}^{X}
$$

\begin{tabular}{|c|c|c|c|c|c|c|c|c|c|c|c|c|}
\hline \multirow{5}{*}{$\begin{array}{l}\text { Lima } \\
\text { Costa Norte } \\
\text { Costa Sur }\end{array}$} & \multicolumn{6}{|c|}{ For a Coastal event } & \multicolumn{6}{|c|}{ For a Global event } \\
\hline & \multicolumn{6}{|l|}{ Lima } & \multicolumn{6}{|l|}{ Lima } \\
\hline & \multicolumn{6}{|c|}{ Costa Norte } & \multicolumn{4}{|c|}{ Costa Norte } & & \\
\hline & $+30,6$ & - & Cost & & & & $+30,6$ & & Cost & Sur & & \\
\hline & $+29,7$ & $+60,3$ & - & Sie & orte & & 0 & $+60,3$ & - & Sierr & Norte & \\
\hline Sierra Norte & $+38,4$ & $+30,6$ & $+68,1$ & - & & Sur & $+38,4$ & $+30,6$ & $+68,1$ & - & Sierı & Sur \\
\hline Sierra Sur & $+29,7$ & $+60,3$ & 0 & 0 & - & Selva & 0 & $+60,3$ & 0 & $+11,6$ & - & Selva \\
\hline Selva & $+38,4$ & $+22,7$ & 0 & 0 & 0 & - & $+38,4$ & $+22,7$ & $+55,2$ & $+21,1$ & $+25,5$ & - \\
\hline
\end{tabular}

Source: own calculations based on Ministry of Transport and Communications (2016), INDECI (2018) and The World Bank (2016)

Notes: (1) Million USD spent annually for a 4-year recovery period after an event. For asphalt pavement, prices per km (are 1.15, 1.31 and 1.34 billion USD for Costa, Sierra and Selva, respectively. For basic pavement, they are 0.37, 0.46 and 0.47 billion USD, respectively. 
Table 5 - Augmented Dickey-Fuller (ADF) test statistics for EI Niño regions' SST anomaly series for 1870-2019

\begin{tabular}{lccccc}
\hline & \multicolumn{2}{c}{ Statistics } & \multicolumn{3}{c}{$\begin{array}{c}\text { Critical values } \\
\text { (1\% level) }\end{array}$} \\
& Tau & Phi & Lags & Tau & Phi \\
& & & & & \\
\hline Pacific regions & & & & & \\
SST 4 & $-7.87^{*}$ & $31.03^{*}$ & 1 & -3.43 & 6.43 \\
SST 1-2 & $-10.76^{*}$ & $57.97^{*}$ & 1 & -3.43 & 6.43 \\
SST 3-4 & $-14.19^{*}$ & $100.67^{*}$ & 1 & -3.43 & 6.43 \\
SST 3 & $-9.30^{*}$ & $43.31^{*}$ & 1 & -3.43 & 6.43 \\
\hline
\end{tabular}

Source: Own calculations based NOAA's HadISST1 dataset

Note: Tau null hypothesis - unit root. Phi null hypothesis - no drift and unit root. $(*)$ Null hypothesis rejected at $1 \%$ level 
Table 6 - Joint distribution function of Global El Niño (columns) and Coastal El Niño (rows) events for a ten-year period (probability in \%)

\begin{tabular}{ccccc}
\hline $\begin{array}{c}\text { Number } \\
\text { of events }\end{array}$ & $\mathbf{0}$ & $\mathbf{1}$ & $\mathbf{2}$ & $\mathbf{3}$ \\
\hline $\mathbf{0}$ & 87.41 & 1.66 & 0.03 & 0.00 \\
$\mathbf{1}$ & 10.03 & 0.19 & 0.00 & 0.00 \\
$\mathbf{2}$ & 0.64 & 0.01 & 0.00 & 0.00 \\
$\mathbf{3}$ & 0.03 & 0.00 & 0.00 & 0.00 \\
\hline
\end{tabular}

Source: Own calculations based on a bootstrap procedure (100 thousand replications) 
Table 7 - Extreme EI Niño event risk profile for Peru over 10 years

\begin{tabular}{|c|c|c|c|c|c|c|c|c|c|c|c|c|c|}
\hline & & \multicolumn{3}{|c|}{ Mean one-off effects of an event ${ }^{(1)}$} & \multicolumn{9}{|c|}{ Average effects of event(s) over the period ${ }^{(2)}$} \\
\hline & & Any event & Coastal & Global & $\mathbf{S C}_{\mathbf{N}}$ & $\mathrm{SC}_{\mathrm{N}=1}$ & $S C_{l .0}$ & $S C_{0.1}$ & $\mathrm{SC}_{\mathrm{N}=2}$ & $S C_{2.0}$ & $S C_{l .1}$ & $S C_{0.2}$ & $\mathrm{SC}_{\mathrm{N}=3}$ \\
\hline & & $P_{n}^{t}=1,35 \%$ & $P_{c}^{t}=1.16 \%$ & $P_{g}^{t}=0.19 \%$ & $P_{N}=12.59 \%$ & $P_{1}=11.69 \%$ & $P_{1.0}=10.03 \%$ & $P_{0.1}=1.66 \%$ & $\mathrm{P}_{2}=0.86 \%$ & $P_{2.0}=0.64 \%$ & $P_{1.1}=0.19 \%$ & $P_{0.2}=0.03 \%$ & $\mathrm{P}_{3}=0.04 \%$ \\
\hline \multicolumn{14}{|l|}{ a. Economic indicators } \\
\hline \multirow{7}{*}{ Real GDP } & National & -2.79 & -2.95 & -1.79 & -0.75 & -0.71 & -0.75 & -0.46 & -1.24 & -1.32 & -1.04 & -0.76 & -1.74 \\
\hline & Lima & -3.02 & -3.26 & -1.57 & -0.76 & -0.72 & -0.77 & -0.41 & -1.26 & -1.36 & -1.02 & -0.68 & -1.79 \\
\hline & Costa Norte & -3.92 & -3.99 & -3.51 & -0.94 & -0.89 & -0.91 & -0.76 & -1.58 & -1.63 & -1.45 & -1.29 & -2.14 \\
\hline & Costa Sur & -2.39 & -2.52 & -1.60 & -0.66 & -0.63 & -0.66 & -0.42 & -1.10 & -1.16 & -0.94 & -0.69 & -1.53 \\
\hline & Sierra Norte & -2.18 & -2.28 & -1.55 & -0.63 & -0.60 & -0.63 & -0.43 & -1.05 & -1.10 & -0.92 & -0.72 & -1.45 \\
\hline & Sierra Sur & -2.25 & -2.42 & -1.25 & -0.65 & -0.62 & -0.66 & -0.36 & -1.09 & -1.17 & -0.89 & -0.60 & -1.53 \\
\hline & Selva & -2.89 & -2.98 & -2.31 & -0.81 & -0.77 & -0.80 & -0.59 & -1.34 & -1.40 & -1.21 & -0.99 & -1.84 \\
\hline \multirow[t]{7}{*}{ Price index } & National & +8.47 & +9.03 & +5.05 & +2.19 & +2.07 & +2.20 & +1.29 & +3.66 & +3.91 & +3.05 & +2.16 & +5.16 \\
\hline & Lima & +7.85 & +8.39 & +4.53 & +2.04 & +1.93 & +2.06 & +1.17 & +3.40 & +3.64 & +2.81 & +1.96 & +4.81 \\
\hline & Costa Norte & +9.56 & +10.07 & +6.43 & +2.46 & +2.33 & +2.45 & +1.61 & +4.10 & +4.34 & +3.53 & +2.69 & +5.73 \\
\hline & Costa Sur & +8.93 & +9.58 & +4.96 & +2.29 & +2.17 & +2.32 & +1.26 & +3.82 & +4.11 & +3.12 & +2.11 & +5.42 \\
\hline & Sierra Norte & +8.37 & +8.86 & +5.37 & +2.17 & +2.05 & +2.17 & +1.36 & +3.62 & +3.84 & +3.08 & +2.28 & +5.08 \\
\hline & Sierra Sur & +9.16 & +9.87 & +4.81 & +2.36 & +2.24 & +2.40 & +1.24 & +3.94 & +4.26 & +3.17 & +2.08 & +5.61 \\
\hline & Selva & +9.43 & +9.89 & +6.59 & +2.42 & +2.29 & +2.41 & +1.64 & +4.05 & +4.27 & +3.53 & +2.75 & +5.64 \\
\hline \multicolumn{14}{|c|}{ b. Households welfare indicators } \\
\hline \multirow{7}{*}{ Real income per capita } & National & -3.21 & -3.41 & -1.99 & -0.75 & -0.71 & -0.75 & -0.45 & -1.27 & -1.36 & -1.05 & -0.76 & -1.77 \\
\hline & Lima & -3.52 & -3.91 & -1.14 & -0.79 & -0.75 & -0.83 & -0.25 & -1.34 & -1.50 & -0.94 & -0.43 & -1.95 \\
\hline & Costa Norte & -5.53 & -5.40 & -6.36 & -1.33 & -1.26 & -1.23 & -1.41 & -2.20 & -2.17 & -2.29 & -2.37 & -2.88 \\
\hline & Costa Sur & -1.60 & -1.72 & -0.87 & -0.42 & -0.40 & -0.43 & -0.21 & -0.71 & -0.77 & -0.55 & -0.35 & -1.00 \\
\hline & Sierra Norte & -1.61 & -1.49 & -2.29 & -0.42 & -0.40 & -0.37 & -0.56 & -0.70 & -0.66 & -0.8 & -0.92 & -0.87 \\
\hline & Sierra Sur & -2.02 & -2.28 & -0.46 & -0.53 & -0.51 & -0.57 & -0.12 & -0.89 & -1.01 & -0.59 & -0.20 & -1.3 \\
\hline & Selva & -1.97 & -1.75 & -3.30 & -0.48 & -0.45 & -0.40 & -0.77 & -0.82 & -0.74 & -1.02 & -1.29 & -0.97 \\
\hline \multirow[t]{7}{*}{ Headcount poverty rate } & National & +1.86 & +1.96 & +1.23 & +0.43 & +0.41 & +0.43 & +0.26 & +0.76 & +0.82 & +0.61 & +0.43 & +1.11 \\
\hline & Lima & +1.61 & +1.77 & +0.66 & +0.36 & +0.33 & +0.37 & +0.12 & +0.65 & +0.74 & +0.42 & +0.19 & +1.02 \\
\hline & Costa Norte & +3.55 & +3.46 & +4.11 & +0.93 & +0.87 & +0.85 & +1.02 & +1.65 & +1.62 & +1.71 & +1.78 & +2.14 \\
\hline & Costa Sur & +0.58 & +0.62 & +0.37 & +0.13 & +0.12 & +0.13 & +0.07 & +0.21 & +0.23 & +0.17 & +0.11 & +0.32 \\
\hline & Sierra Norte & +1.19 & +1.12 & +1.63 & +0.28 & +0.27 & +0.25 & +0.37 & +0.47 & +0.44 & +0.54 & +0.63 & +0.60 \\
\hline & Sierra Sur & +1.72 & +1.91 & +0.57 & +0.37 & +0.35 & +0.39 & +0.12 & +0.60 & +0.67 & +0.41 & +0.18 & +0.87 \\
\hline & Selva & +1.42 & +1.30 & +2.15 & +0.30 & +0.28 & +0.25 & +0.49 & +0.52 & +0.46 & +0.67 & +0.87 & +0.62 \\
\hline
\end{tabular}

Source: Own calculations with GAMS software

Notes: (1) Relative deviation from $\mathrm{Sc}_{\mathrm{BAU}}$ values (in \%) for a year of occurrence (except for poverty rate for which is the absolute deviation); (2) Average annual relative deviation (in \%) from Sc $\mathrm{BAU}_{\mathrm{BAU}}$ values over the period (except for poverty rate for which is the absolute deviation) 


\section{Table 8 - Reduction of effects on GDP and poverty expected for different preventive action plans for Peruvian road networks over 10 years}

\begin{tabular}{|c|c|c|c|c|c|c|c|}
\hline & \multicolumn{3}{|c|}{$\begin{array}{c}\text { For mean one-off effects of an } \\
\text { event }\end{array}$} & \multicolumn{4}{|c|}{ For average effects of event(s) over the period } \\
\hline & $\begin{array}{c}\text { Any } \\
\text { event }\end{array}$ & $\begin{array}{c}\text { Coastal } \\
\text { event }\end{array}$ & $\begin{array}{c}\text { Global } \\
\text { event }\end{array}$ & $\mathbf{S C}_{\mathrm{N}}$ & $\mathrm{SC}_{\mathrm{N}=1}$ & $\mathbf{S C}_{\mathrm{N}=2}$ & $\mathrm{SC}_{\mathrm{N}=3}$ \\
\hline & $P_{n}^{t}=1,35 \%$ & $P_{c}^{t}=1.16 \%$ & $P_{g}^{t}=0.19 \%$ & $P_{N}=12.59 \%$ & $P_{1}=11.69 \%$ & $P_{2}=0.86 \%$ & $P_{3}=0.04 \%$ \\
\hline \multicolumn{8}{|c|}{ Upgrading critical first best roads } \\
\hline For events' impact on GDP & $-42 \%$ & $-42 \%$ & $-43 \%$ & $-21 \%$ & $-20 \%$ & $-38 \%$ & $-45 \%$ \\
\hline For events' impact on poverty & $-44 \%$ & $-43 \%$ & $-52 \%$ & $-61 \%$ & $-62 \%$ & $-58 \%$ & $-61 \%$ \\
\hline \multicolumn{8}{|c|}{ In the most impacted regions only } \\
\hline For events' impact on GDP & $-48 \%$ & $-47 \%$ & $-53 \%$ & $-44 \%$ & $-43 \%$ & $-53 \%$ & $-54 \%$ \\
\hline For events' impact on poverty & $-44 \%$ & $-43 \%$ & $-52 \%$ & $-62 \%$ & $-63 \%$ & $-61 \%$ & $-61 \%$ \\
\hline \multicolumn{8}{|c|}{ Upgrading extant second best roads } \\
\hline For events' impact on GDP & $-47 \%$ & $-47 \%$ & $-50 \%$ & $-38 \%$ & $-37 \%$ & $-48 \%$ & $-53 \%$ \\
\hline For events' impact on poverty & $-47 \%$ & $-45 \%$ & $-57 \%$ & $-73 \%$ & $-74 \%$ & $-65 \%$ & $-66 \%$ \\
\hline \multicolumn{8}{|c|}{ In the most impacted regions only } \\
\hline For events' impact on GDP & $-54 \%$ & $-53 \%$ & $-63 \%$ & $-70 \%$ & $-70 \%$ & $-66 \%$ & $-65 \%$ \\
\hline For events' impact on poverty & $-47 \%$ & $-45 \%$ & $-56 \%$ & $-71 \%$ & $-71 \%$ & $-63 \%$ & $-65 \%$ \\
\hline
\end{tabular}

Source: Own calculations with GAMS software

Note: All effects are compared to the same scenario without the preventive action plan 
Table 9 - Effectiveness indicators for different preventive action plans on Peruvian road networks over 10 years ${ }^{(1)(2)}$

\begin{tabular}{|c|c|c|c|}
\hline & $\begin{array}{l}\text { Expected } \\
\text { value }\end{array}$ & $\begin{array}{c}\mathrm{SC}_{\mathrm{BAU}} \\
\text { (No event) } \\
P_{B A U}=87.41 \%\end{array}$ & $\begin{array}{c}\mathrm{SC}_{\mathbf{N}} \\
\text { (At least one event) } \\
P_{N}=12.59 \%\end{array}$ \\
\hline \multicolumn{4}{|l|}{ Upgrading critical first best roads } \\
\hline \multicolumn{4}{|l|}{ At national level } \\
\hline Annual cost of policy (Million USD) & 640 & 640 & 640 \\
\hline GDP-Benefit-cost ratio & -36 & -45 & 28 \\
\hline Poverty-Benefit-cost ratio & 147 & 0 & 1166 \\
\hline \multicolumn{4}{|l|}{ In the most impacted regions only } \\
\hline Annual cost of policy (Million USD) & 265 & 265 & 265 \\
\hline GDP-Benefit-cost ratio & -23 & -45 & 132 \\
\hline Poverty-Benefit-cost ratio & 358 & 0 & 2841 \\
\hline \multicolumn{4}{|l|}{$\begin{array}{l}\text { Upgrading extant second best roads } \\
\text { At national level }\end{array}$} \\
\hline Annual cost of policy (Million USD) & 779 & 779 & 779 \\
\hline GDP-Benefit-cost ratio & -13 & -21 & 39 \\
\hline Poverty-Benefit-cost ratio & 157 & 18 & 1124 \\
\hline \multicolumn{4}{|l|}{ In the most impacted regions only } \\
\hline Annual cost of policy (Million USD) & 125 & 125 & 125 \\
\hline GDP-Benefit-cost ratio & 101 & 55 & 424 \\
\hline Poverty-Benefit-cost ratio & 929 & 82 & 6810 \\
\hline
\end{tabular}

Source: Own calculations with GAMS software.

Notes: (1) GDP-Benefit-cost ratio is the net gain (in Million USD) in real GDP over the period for one Million USD invested annually; (2) Poverty-Benefit-cost ratio is the absolute reduction of the number of poor over the period for one Million USD invested annually. 


\section{LIST OF FIGURES}

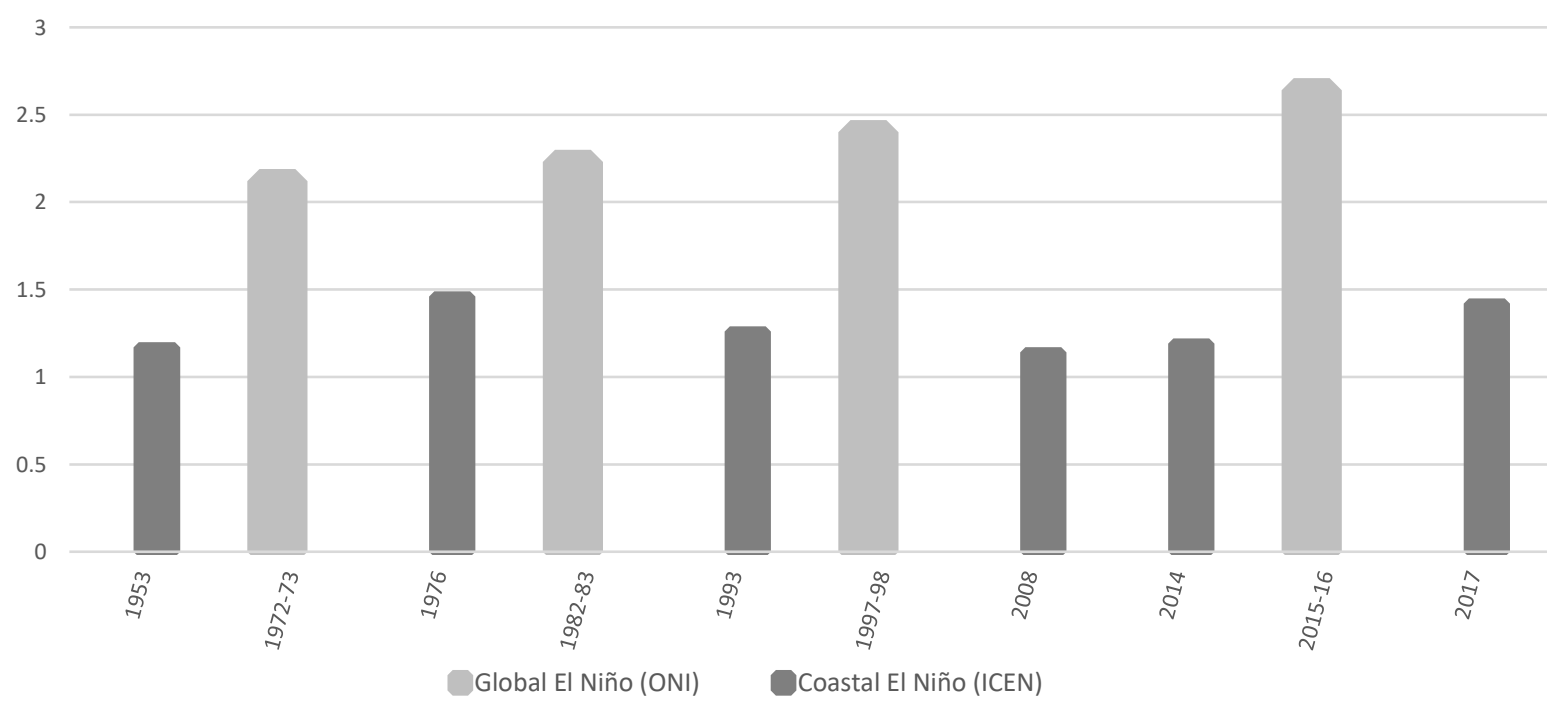

Figure 1 - Occurrence of extreme EI Niño events in Peru over the 1950-2020 period. Sources: Own calculations based on ENFEN database and NOAA database. Note: Greater value observed for the 3month running mean of SST anomalies during a year (level thresholds $\geq 2$ for ONI and $\geq 1.1$ for ICEN). 


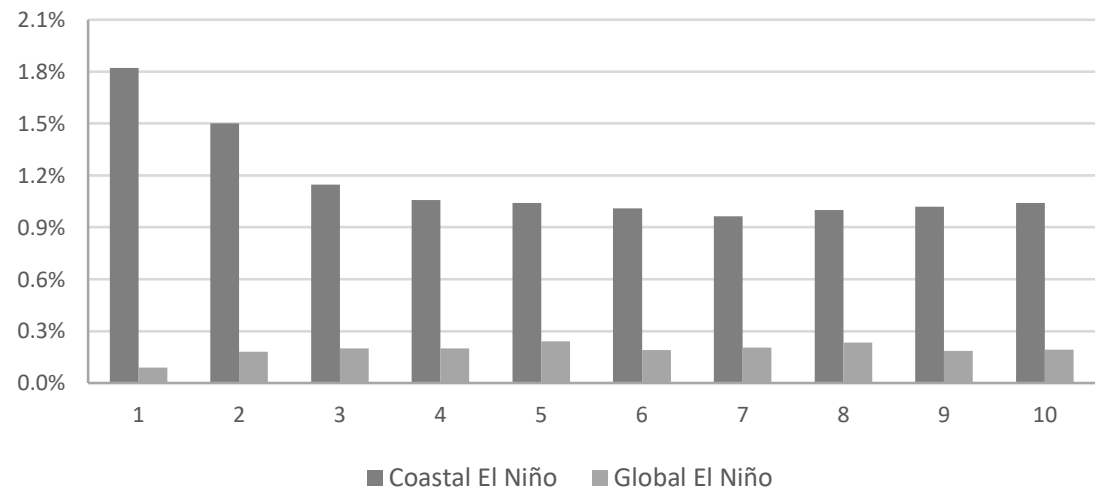

Figure 2 - Annual probabilities of occurrence of Global El Niño and Coastal El Niño events over 10 years. Source: Own estimate based on a VAR model and a bootstrap procedure (100 thousand replications) 
Effects on real GDP

(Annual relative deviation in \% from BAU)

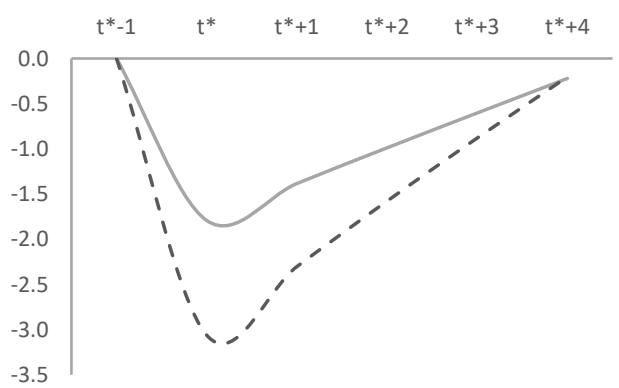

Effects on Price index

(Annual relative deviation in \% from BAU)

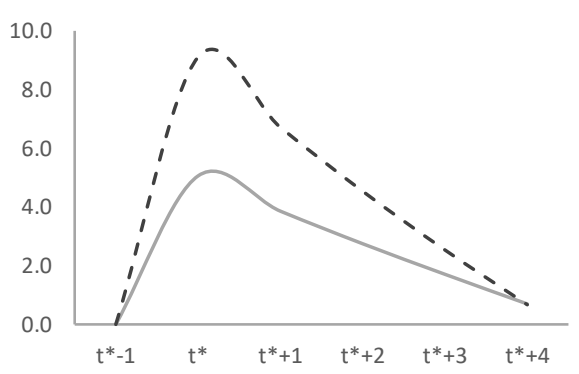

Effects on Poverty rate

(Annual absolute deviation in \% from BAU)

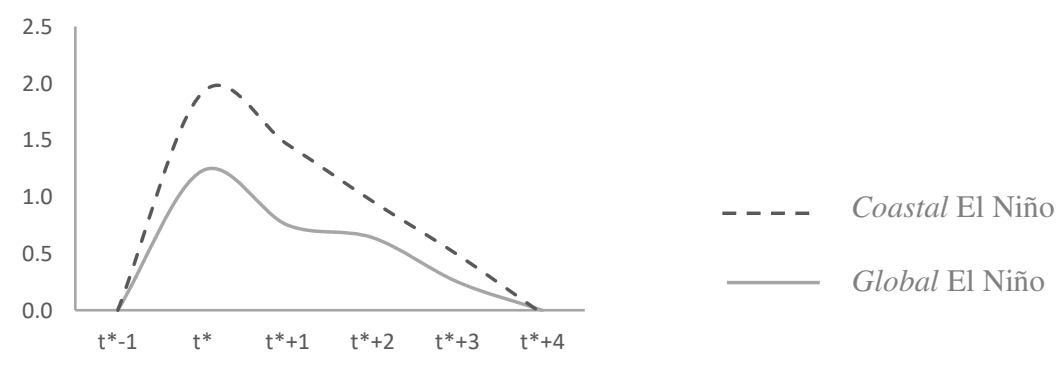

Figure 3 - Selected one-off effects of extreme El Niño event-related road damages for a year of occurrence $t^{*}$ and until the recovery process completes. Source: Own calculations with GAMS software 
Effects on real GDP

(Relative deviation in \% from BAU)

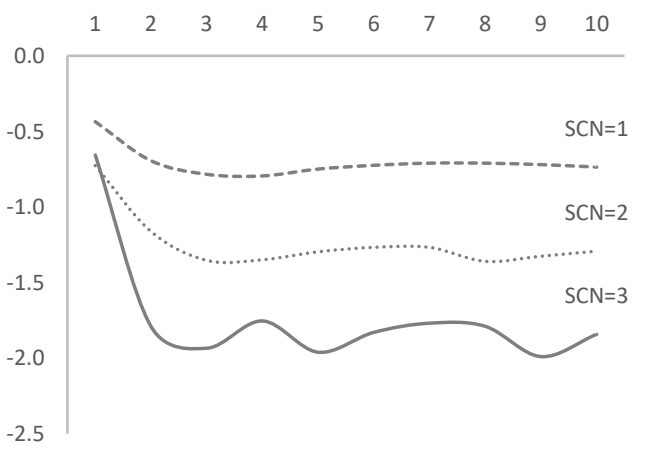

Effects on Price index

(Relative deviation in \% from BAU)

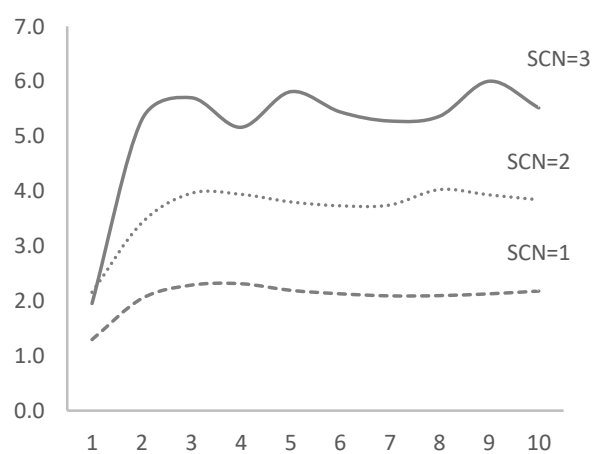

Effects on Poverty rate

(Absolute deviation in \% from BAU)

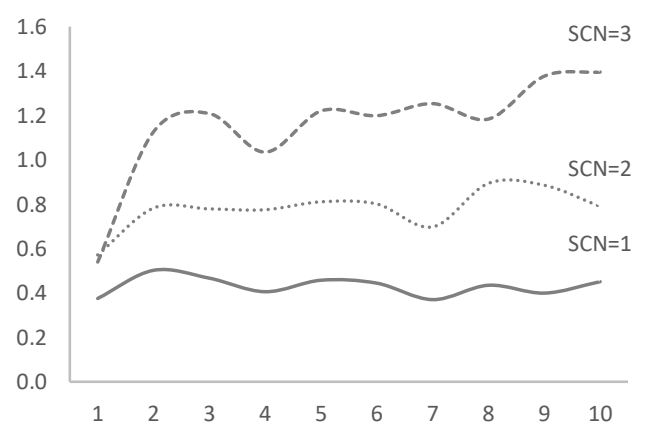

Figure 4 - Selected average effects over a 10-year period of extreme El Niño event-related road damages in each stochastic scenario. Source: Own calculations with GAMS software.

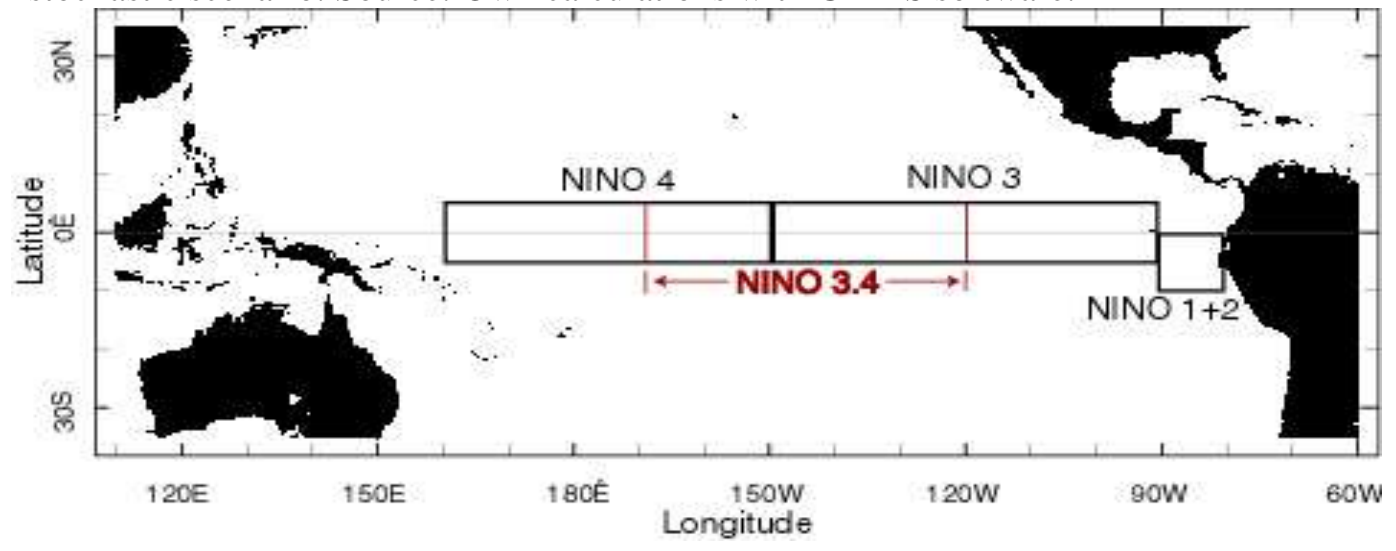

Map 1 - Regions of the Pacific Ocean used for identifying an El Niño event. Source: NOAA 


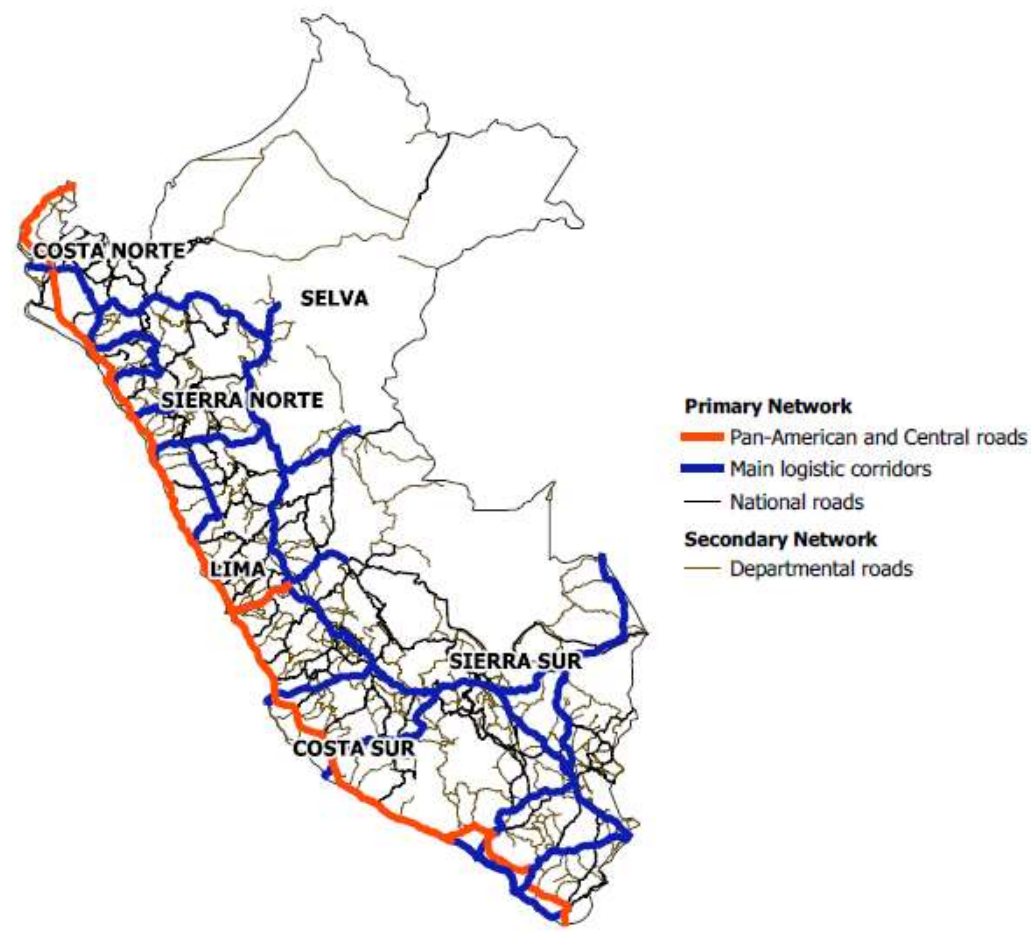

Map 2 - Current structure of road network in Peru. Source: Based on Ministry of Transport and Communications (2016) 


\section{APPENDIX (SUPPLEMENTARY MATERIAL) \\ MR-CGE Model for Peru}

\section{I - Institutional desegregation and model sets}

\section{Institutions' desegregation}

Activities or products $(6 \times 10=60)$

Agriculture

Fishing

Mining

Manufacture

Electricity and water

Construction

Trade

Transport

Other private services

Public administration

Agents (8)

Households (1 by region)

National government $(G)$

Rest of the world (Row)

\section{Sets and indexing}

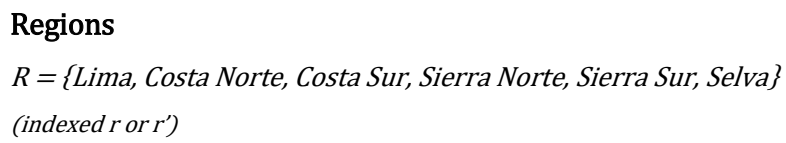

Time periods

$\mathrm{T}=\{0,1,2,3,4,5,6,7,8,9,10\}$

(indexed $t$ ) 


\section{II - Model equations}

\section{Within-period specifications}

\subsection{Production}

(1) $V A_{j, r, t}=\theta_{j, r, t}^{R O A D} \cdot A_{j, r}^{V A} \cdot L D C_{j, r, t}^{\alpha j_{j}^{\prime A}} \cdot K_{j, r, t}^{1-\alpha_{j, r}^{\nu A}}$

(2) $V A_{j, r, t}=v_{j, r} X S T_{j, r, t}$

(3) $C I_{j, r, t}=i o_{j, r} . X S T_{j, r, t}$

(4) $L D C_{j, r, t}=\frac{\alpha_{j, r}^{Y A} P V A_{j, r, t}}{W C_{j, r, t}}$

(5) $L D C_{j, r, t}=B_{j, r .}^{L}\left[\beta_{j, r}^{L} \cdot L D u_{j, r, t}^{\rho_{j, r}^{L}}+\left(1-\beta_{j, r}^{L}\right) \cdot L D s k_{j, r, t}^{\rho_{j, r}^{L}}\right]^{\frac{1}{\rho_{j, r}^{L}}} \forall j, r$

(6) $L D u_{j, r, t}=L D s k_{j, r, t} \cdot\left[\frac{1-\beta_{j, r}^{L}}{\beta_{j, r}^{L}} \cdot \frac{w u_{u}}{w s k_{t}}\right]^{\sigma_{j, r}^{L}}$

\subsection{Income and savings}

Households

(7) $Y H_{r, t}=R T L_{r, t}+R T K_{r, t}^{H}+\overline{R T R_{r, t}^{H}} \quad \forall r$

(8) $R T L_{r, t}=w u_{t} \cdot \Sigma_{j} L D u_{j, r, t}+w s k_{t} \cdot \sum_{j} L D s k_{j, r, t} \quad \forall r$

(9) $R T K_{r, t}^{H}=\sum_{r,} \sum_{j} \lambda_{K, r}^{H} \cdot R_{j, r, t, t} \cdot K_{j, r, t} \quad \forall r$

(10) $Y D H_{r, t}=Y H_{r, t}-T D H_{r, t}^{H}$

(11) $T D H_{r, t}=P I X C O N_{t} \cdot t d h_{t}^{0}+t d h_{t .}^{1} Y H_{r, t}$

(12) $C T H_{r, t}=Y D H_{r, t}-S H_{r, t}$

(13) $S H_{r, t}=\operatorname{PIXCON}_{t} \cdot s h_{t}^{0}+\operatorname{sh}_{t .}^{1} Y D H_{r, t}$

Government

(14) $Y G_{t}=R T K_{t}^{G}+\overline{R T R_{t}^{G}}+\sum_{r} T D H_{r, t}+T I M T_{t}+T_{I C T_{t}}+$ TIPT

(15) $R T K_{t}^{G}=\sum_{r} \sum_{j} \lambda_{K, r}^{G} \cdot R_{j, r, t} \cdot K_{j, r, t}$

(16) $\operatorname{TIMT}_{t}=E R_{t} \cdot \sum_{r} \sum_{i} t i m_{i} \cdot \overline{P W M_{l, t}} \cdot I M_{i, t}$

(17) TICT $_{t}=\sum_{r} \sum_{r,} \sum_{i} P X S L_{i, r^{\prime}, r, t} . X S L_{i, r^{\prime}, r, t}$

(18) $T I P T_{t}=\sum_{r} \sum_{j} t i p_{j} \cdot P P_{j, r, t} \cdot X S T_{j, r, t}$

(19) $S G_{t}=Y G_{t}-G_{t}$

\subsection{Demand}

Final Consumption

(20) $P C_{i, r, t} \cdot C G_{i, r, t}=\gamma_{i, r}^{C G} \cdot \overline{G_{t}} \quad \forall i, r$

(21) $P C_{i, r, t} \cdot C_{i, r, t}=P C_{i, r, t} \cdot c_{i, r, t}^{M i n}+p m c_{i, r} \cdot\left[C T H_{r, t}-\right.$

$$
\left.\sum_{i^{\prime} \neq i} P C_{i^{\prime}, r, t} \cdot C_{i^{\prime}, r, t}^{\text {Min }}\right]
$$

$\forall i, r$

Intermediate consumption

(22) $D I_{i, r, t}=\sum_{r} \sum_{j} a i j_{i, j, r} \cdot C I_{j, r, t}$

$\forall i, r$ Investment

(23) $I N V_{i, r, t}=I N V P_{i, r, t}+I N V G_{i, r, t}+I N V G_{i, r, t}^{\text {Road }} \quad \forall i, r$

(24) $P C_{i, r, t} \cdot I N V G_{i, r, t}=\gamma_{i, r}^{I G} \cdot I G_{t} \quad \forall i, r$

(25) $P C_{i, r, t} . I N V P_{i, r, t}=\gamma_{i, r}^{I P} . I P_{t} \quad \forall i, r$

(26) $P C_{i, r, t} \cdot I N V G_{i, r, t}^{\text {Road }}=\gamma_{i, r}^{\text {IRoad }} \cdot \overline{\operatorname{Inv}_{r, t}^{\text {Rood }}} \quad \forall i, r$

\subsection{Regional, national and international trade}

Allocation of output between domestic markets and exports

(27) $X S T_{j, r, t}=X S_{i, r, t} \quad \forall i \in I \approx j \in J$ and $\forall r$

(28) $X S_{i, r, t}=B_{i, r}^{X}\left[\beta_{i, r}^{X} E X_{i, r, t}^{\rho_{i, r}^{X}}+\left(1-\beta_{i, r}^{X}\right) \cdot X S L_{i, r, t}^{\rho_{i, r}^{X}}\right]^{\frac{1}{\rho_{i, r}^{X}}} \quad \forall i, r$

(29) $E X_{i, r, t}=X S L_{i, r, t} \cdot\left[\frac{1-\beta_{i, r}^{X}}{\beta_{i, r}^{X}} \cdot \frac{P E_{i, r}^{F} F B}{P X L_{i, r}, t}\right]^{\sigma_{i, r}^{X}} \quad \forall i, r$

(30) $E X D_{i, r, t}=E X D_{i, r, t}^{o} \cdot \operatorname{pop}(t) \cdot E R_{t} \cdot\left[\frac{\overline{P W X_{L t}}}{\frac{P E_{i, r}^{C L}}{C l E}}\right]^{\sigma_{i}^{X D}} \quad \forall i, r$

Allocation of domestic output between regions

(31) $X S L_{i, r, t}=B_{i, r}^{R} \cdot\left[\sum_{r}, \beta_{i, r, r}^{R} . X S R_{i, r^{\prime}, r, t}^{\rho_{i, r}^{R}}\right]^{\frac{1}{\rho_{i, r}^{R}}} \quad \forall i, r$

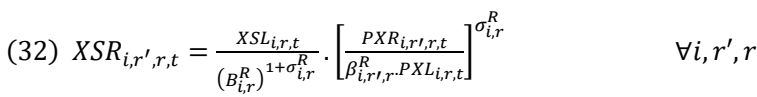

Peruvian composite goods demanded in region $r$

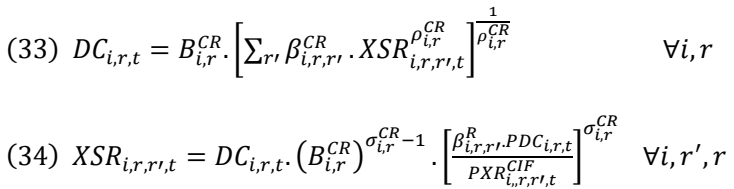


Composite goods of Peruvian goods and imports demanded in region $r$

(35) $Q_{i, r, t}=B_{i, r}^{M}\left[\beta_{i, r}^{M} \cdot I M_{i, r, t}^{-\rho_{i, r}^{M}}+\left(1-\beta_{i, r}^{M}\right) \cdot D D_{i, r, t}^{-\rho_{i, r}^{M}}\right]^{\frac{1}{\rho_{i, r}^{M}}} \quad \forall i, r$

(36) $I M_{i, r, t}=D C_{i, r, t} \cdot\left[\frac{\beta_{i, r}^{M}}{1-\beta_{i, r}^{M}} \cdot \frac{P D_{i, r}, t}{P M_{i, t}}\right]^{\sigma_{i, r}^{M}}$

$\forall i, r$

Demand for transport services

(37) $T R P R_{i, r, r, t, t}=\operatorname{transp}_{i, r, r, r, t}^{R} . X S R_{i, r, r, t} \quad \forall i, r^{\prime}, r$

(38) $T R P X_{i, r, t}=\operatorname{transp}_{i, r, t}^{X} \cdot E X_{i, r, t}$

$\forall i, r$

\subsection{Closure rules}

Product markets

(39) $D C_{i, r, t}=D D_{i, r, t}$

(40) $Q_{i, r, t}=\sum_{r} C_{i, r, t}+\sum_{r} C G_{i, r, t}+\sum_{r} I N V_{i, r, t}+\sum_{r} D I T_{i, r, t} \forall i, r$

(41) $Q_{\text {Trans }, r, t}=\sum_{r} C_{i, r, t}+\sum_{r} C G_{i, r, t}+\sum_{r} I N V_{i, r, t}+$

$\sum_{r} D_{T} T_{i, r, t}+\operatorname{TRANS}_{r, t}^{R}+\operatorname{TRANS}_{r, t}^{X}$

(42) $T R A N S_{r, t}^{R}=\sum_{r}, \sum_{i} T R P R_{i, r, r, t}$

$\forall r$

(43) $T R A N S_{r, t}^{X}=\sum_{r}, \sum_{i} T R P X_{i, r, t}$

$\forall r$

Labour market

(44) $\sum_{r} \overline{L S u_{j, r, t}}=\sum_{r} \sum_{j} L D u_{j, t}$

(45) $\sum_{r} \overline{L S s k_{J, r, t}}==\sum_{r} \sum_{j} L D s k_{j, t}$

Capital market

(46) $\sum_{r}\left(I P_{r, t}+I G_{r, t}+\overline{I G_{r, t}^{R o a d}}\right)=\sum_{r} S H_{r, t}+S G_{t}-C A B_{t}$

Current account balance

(47) $\overline{C A B_{t}}=\sum_{r} \sum_{i} P E_{i, r, t} \cdot E X_{i, r, t}-\sum_{r} \sum_{j} \lambda_{K, r}^{R O W} \cdot R_{j, r, t} \cdot K D_{j, r, t}-$ $\overline{R T R_{t}^{R O W}}-E R_{t} \cdot \sum_{r} \sum_{i} \overline{P W M_{l, t}} \cdot I M_{i, r, t}$

Numeraire

(48) $E R_{t}=1$

\subsection{Price system}

(49) $P P_{j, r, t} . X S T_{j, r, t}=P V A_{j, r, t} \cdot V A_{j, r, t}+\sum_{i} P C_{i, r, t} \cdot D I_{i, r, t} \quad \forall j, r$

(50) $P T_{j, r, t}=\left(1+t i p_{j}\right) \cdot P P_{j, r, t} \quad \forall j, r$

(51) $P V A_{j, r, t} \cdot V A_{j, r, t}=W C_{j, r, t} . L D C_{j, r, t}+R_{j, r, t} \cdot K_{j, r, t} \quad \forall j, r$

(52) $P_{i, r, t}=P T_{j, r, t} \quad \forall i \in I \approx j \in J$ and $\forall r$

(53) $P_{i, r, t} . X S_{i, r, t}=P E_{i, t} \cdot E X_{i, r, t}+P X L_{i, r, t} \cdot X S L_{i, r, t} \quad \forall i, r$

(54) $P X L_{i, r, t} . X S L_{i, r, t}=\sum_{r} P X R_{i, r \prime, r, t}^{F O B} . X S R_{i, r^{\prime}, r, t} \quad \forall i, r$
(55) $P X R_{i, r, r, t, t}^{C I F}=P X R_{i, r, r, t}^{F O B}+P C_{\text {Trans }, r, t} \cdot$ transp $_{i, r, r, t}^{R}$

(56) $P E_{i, r, t}^{C I F}=P E_{i, r, t}^{F O B}+P C_{\text {Trans }, r, t} \cdot$ transp $_{i, r, t}^{X}$

(57) $P M_{i, t}=\left(1+t i c_{i}\right) \cdot\left(1+t i m_{i}\right) \cdot E R_{t} \cdot \overline{P W M_{l, t}}$

(58) $P D C_{i, r, t} \cdot D C_{i, r, t}=\sum_{r,} P X R_{i, r, r, t}^{C I F} \cdot X S R_{i, r, r r, t} \quad \forall i, r$

(59) $P D_{i, r, t}=\left(1+t i c_{i}\right) \cdot P D C_{i, r, t} \quad \forall i, r$

(60) $P C_{i, r, t} \cdot Q_{i, r, t}=P M_{i, r, t} \cdot I M_{i, r, t}+P D_{i, r, t} \cdot D D_{i, r, t} \quad \forall i, r$

(61) PIXCON $_{t}=\sum_{i} P C_{i, r, t} \cdot \sum_{r} C_{i, r}^{o} / \sum_{i \prime} P C_{i \prime, t} \cdot \sum_{r} C_{i \prime, r}^{o}$

\section{Between-period specifications}

\section{Capital accumulation in each activity}

(62) $K D_{j, r, t+1}=K D_{j, r, t} \cdot\left(1-\delta_{j, r, t}\right)+I N D_{j, r, t} \quad \forall j, r$

(63) $I N D_{b u s, r, t}=K_{b u s, r, t} \cdot \emptyset_{b u s, r} \cdot\left[\frac{R_{b u s, r, t}}{U_{b u s, r, t}}\right]^{\sigma_{b u s, r}^{I N V}} \quad \forall b u s, r$

(64) $U_{b u s, r, t}=P K_{t} \cdot\left(\delta_{b u s, r}+\overline{I R_{t}}\right) \quad \forall b u s, r$

(65) $P K_{t}=\frac{1}{A^{K}} \cdot \prod_{i, r}\left[\frac{P C_{i, r, t}}{\gamma_{i, r}^{K}}\right]^{\gamma_{i, r}^{K}} \quad \forall r$

(66) $I P_{t}=P K_{r, t} \cdot \sum_{b u s} I N D_{b u s, r, t} \quad \forall r$

(67) $I G_{t}=P C_{p u b, r, t} \cdot \sum_{p u b} \overline{I N D_{p u b, r, t}} \quad \forall r$

\section{Simulation rules}

\subsection{For road network infrastructure}

Evolution of road network

(68) $\operatorname{Road}_{r, t}=\operatorname{Road}_{r, t-1} \cdot\left(1-\overline{\operatorname{Niño}_{r, t}} \cdot \overline{\Delta \operatorname{road}_{r}}\right)+\overline{\left(\operatorname{Inv} v_{r, t}^{\text {Road }}\right)}$ With:

$\overline{N_{\mathrm{n} n} o_{r, t}}=1$ if $t$ is a year $t$ of occurence or 0 if not

$0 \leq \overline{\operatorname{road}_{r}}<1$

$\overline{I n v_{r, t}^{\text {Road }}}$ are only relevant over 4 years after an event

Externality effects on private activities

(69) $\theta_{j, r, t}^{R O A D}=\left[\frac{\text { Road }_{t}}{\text { Road }_{t-1}}\right]^{\varepsilon_{j, r}^{\text {road }}} \quad \forall j \in$ BUS and $\forall r$

3.2 For transportation costs

(70) $\operatorname{transp}_{i, r^{\prime}, r, t}^{R}=\overline{\operatorname{transp}_{l, r, r, r, t o}^{R}} \cdot\left(1+\overline{\operatorname{Nlño}_{r, t}} \cdot \overline{\Delta \operatorname{tr}_{l, r^{\prime}, r}^{R}}\right)$

(71) $\operatorname{transp}_{i, r, t}^{X}=\overline{\operatorname{transp}_{l, r, t o}^{X}} \cdot\left(1+\overline{N i \tilde{n} o_{r, t}} \cdot \overline{\Delta \operatorname{tr}_{l, r}^{X}}\right)$ 
With $\overline{N i n ̃ O_{r, t}}=1$ if $t$ is a year $t$ of occurence or 0 if not

3.3 For exogenous variables and for parameters

(72) $\operatorname{pop}_{t+1}=\operatorname{pop}_{t} \cdot\left(1-n_{t}\right)$ with pop $0=1$

(73) $\overline{L S u_{j, r, t+1}}=p o p_{t} \cdot L S u_{j, r, 0}$

(74) $\overline{L S s k_{\jmath, r, t+1}}=\operatorname{pop}_{t} \cdot L S s k_{j, r, 0}$

(75) $\overline{I N D_{p u b, r, t+1}}=p o p_{t} \cdot I N D_{p u b, r, 0}$

(76) $\overline{C A B_{t+1}}=\operatorname{pop}_{t} \cdot C A B_{0}$

(77) $\overline{G_{t+1}}=\operatorname{pop}_{t} \cdot G_{0}$

(78) $\overline{\operatorname{RTR}_{r, t}^{H}}=\operatorname{pop}_{t} \cdot$ PIXCON $\cdot$.TR $R_{r, 0}^{H}$

(79) $\overline{R T R_{t}^{G}}=\operatorname{pop}_{t} \cdot$ PIXCON $\cdot$ TR $R_{r, 0}^{G}$
(80) $\overline{R T R_{t}^{R o w}}=\operatorname{pop}_{t} \cdot$ PIXCON ${ }_{t} \cdot T R_{r, 0}^{\text {Row }}$

(81) $c_{i, r, t+1}^{\text {Min }}=\operatorname{pop}_{t} \cdot c_{i, r, 0}^{\mathrm{Min}}$

(82) $s h_{t+1}^{0}=p o p_{t} \cdot s h_{0}^{0}$

(83) $t d h_{r, t+1}^{0}=\operatorname{pop}_{t} \cdot t d h_{r, 0}^{0}$

\section{Microeconomic module}

(I) $E C_{r, i}^{t}=\frac{C_{r, i}^{t}}{\prod_{k=1}^{K}\left(\frac{p_{r, k}^{t}}{p_{r, k}^{0}}\right)^{w_{r, k, i}}}$

(II) Poverty ${ }_{r}^{t}=\frac{1}{N_{r}} \sum_{i=1}^{q}\left[\frac{L-E C_{i}^{t}}{L}\right]$ 


\section{List of variables and parameters}

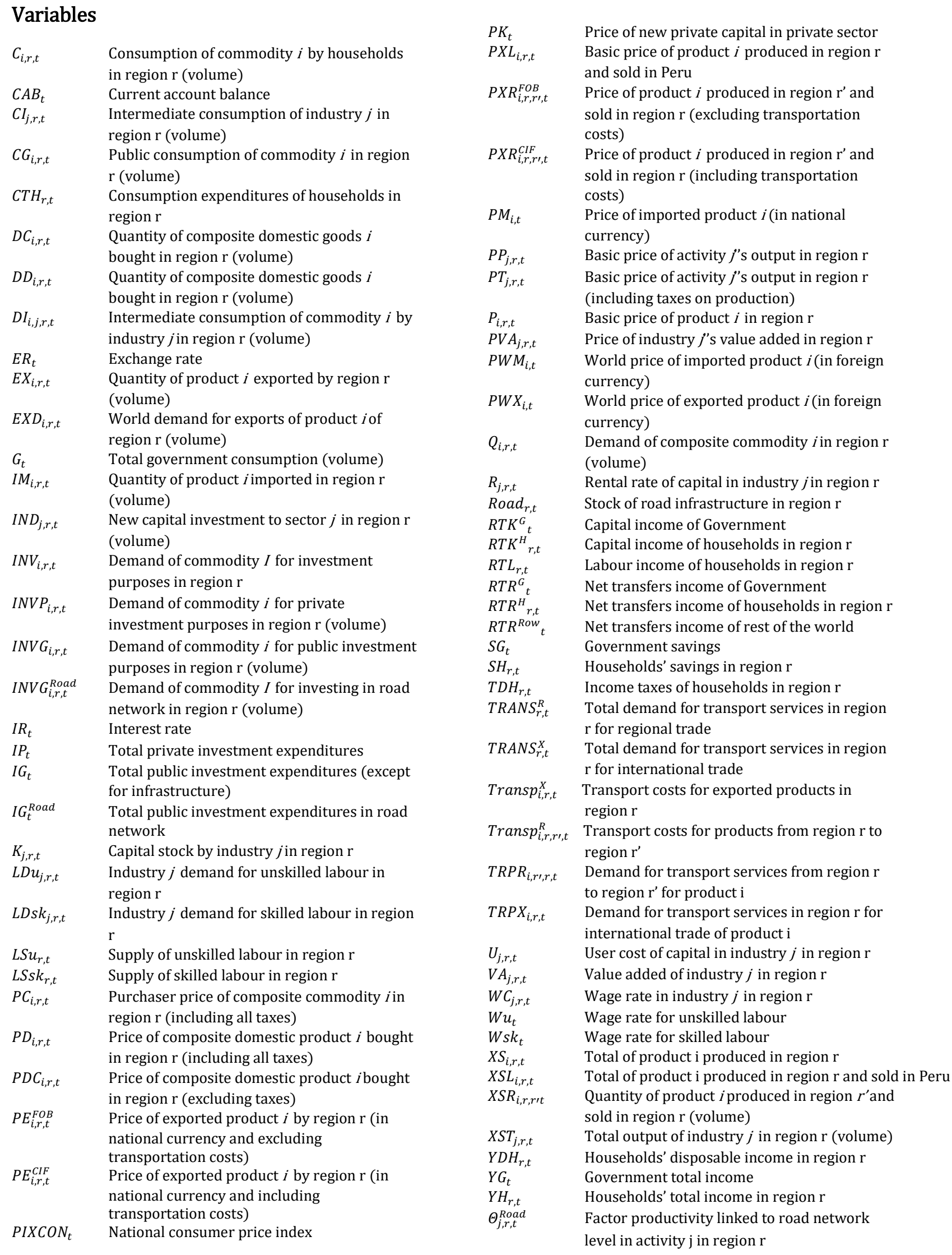




\section{Parameters}

$c_{i, r, t}^{\text {Min }} \quad$ Minimum consumption of commodity $i$ by households in region $\mathrm{r}$ (volume)

$i o_{j} \quad$ Leontief coefficient for intermediate consumption

$v_{j} \quad$ Leontief coefficient for value added

$A_{j, r}^{V A} \quad$ Scale parameter for value-added production function of activity $\mathrm{j}$ in region $\mathrm{r}$

$\alpha_{j, r}^{V A} \quad$ Elasticity parameter for value-added production function of activity $\mathrm{j}$ in region $\mathrm{r}$

$B_{j, r}^{L} \quad$ Scale parameter for CES - composite labour function of activity $\mathrm{j}$ in region $\mathrm{r}$

$\beta_{j, r}^{L} \quad$ Share parameter for CES - composite labour function of activity $\mathrm{j}$ in region $\mathrm{r}$

$\rho_{j, r}^{L} \quad$ Elasticity parameter for CES - composite labour function of activity $\mathrm{j}$ in region $\mathrm{r}$

$a i j_{i, j, r} \quad$ Input-output coefficient of activity $\mathrm{j}$ in region $\mathrm{r}$

$\lambda_{K, r}^{H} \quad$ Share of capital income received by households in region $\mathrm{r}$

$\lambda_{K}^{G} \quad$ Share of capital income received by the Government

$\lambda_{K}^{R o w} \quad$ Share of capital income received by the rest of the world

$s h o_{r, t} \quad$ Savings function intercept for households in region $\mathrm{r}$

$s h 1_{r, t} \quad$ Savings function slope for households in region $\mathrm{r}$

$t d h o_{r, t} \quad$ Taxation function intercept for households in region $\mathrm{r}$

$t d h 1_{r, t} \quad$ Marginal income tax rate of households in region $r$

$\operatorname{tim}_{i} \quad$ Rate of taxes and duties on imports of commodity $i$

tic $_{i} \quad$ Tax rate on commodity $i$

$\operatorname{tip}_{j} \quad$ Tax rate on production $j$

pop $_{t} \quad$ Population index

$P m c_{i, r} \quad$ Marginal share of commodity $i$ in households' consumption budget in region $\mathrm{r}$

$\lambda_{i, r}^{C G} \quad$ Share of commodity $i$ in total current public expenditures in region $\mathrm{r}$

$\lambda_{i, r}^{I P} \quad$ Share of commodity $i$ in total private investment expenditure in region $\mathrm{r}$

$\lambda_{i, r}^{I G} \quad$ Share of commodity $i$ in total public non-road investment expenditure in region $\mathrm{r}$

$\varepsilon_{j, r}^{\text {Road }} \quad$ Elasticity of value added relative to road network in region $\mathrm{r}$

$B_{i, r}^{R}$

$\beta_{i, r}^{R}$

Scale parameter for CET - Region function in region $r$

Share parameter for CET - Region function in region $r$

$\rho_{i, r}^{R} \quad$ Elasticity parameter for CET - Region function in region $\mathrm{r}$

$\sigma_{i, r}^{R} \quad$ Elasticity of transformation for CET - Region function in region $\mathrm{r}$

$B_{i, r}^{X} \quad$ Scale parameter for CET - Export function in region $\mathrm{r}$

$\beta_{i, r}^{X} \quad$ Share parameter for CET - Export function in region $\mathrm{r}$

$\rho_{i, r}^{X} \quad$ Elasticity parameter for CET - Export function in region $\mathrm{r}$

$\sigma_{i, r}^{X} \quad$ Elasticity of transformation for CET - Export function in region $\mathrm{r}$

$\sigma_{i, r}^{X D} \quad$ Price-elasticity of the world demand for exports of product $i$ in region $\mathrm{r}$

$B_{i, r}^{M} \quad$ Scale parameter for CES - composite domestic and import function in region $\mathrm{r}$

$\beta_{i, r}^{M} \quad$ Share parameter for CES - composite domestic and import function in region $\mathrm{r}$

$\rho_{i, r}^{M} \quad$ Elasticity parameter for CES - composite domestic and import function in region $\mathrm{r}$

$\sigma_{i, r}^{M} \quad$ Elasticity of substitution for CES - composite domestic and import function in region $\mathrm{r}$

$B_{i, r}^{C R} \quad$ Scale parameter for CES -composite regional goods function in region $\mathrm{r}$

$\beta_{i, r}^{C R} \quad$ Share parameter for CES - composite regional goods function in region $\mathrm{r}$

$\rho_{i, r}^{C R} \quad$ Elasticity parameter for CES - composite regional goods function in region $\mathrm{r}$

$\sigma_{i, r}^{C R} \quad$ Elasticity of substitution for CES - composite regional goods function in region $\mathrm{r}$

$A^{K} \quad$ Scale parameter for private investment demand function in region $\mathrm{r}$

$\phi_{b u s, r} \quad$ Scale parameter for allocation of investment to private industries in region $r$

$\sigma_{b u s, r}^{I N V} \quad$ Elasticity of private investment demand relative to Tobin's $q$ in region $\mathrm{r}$
$n_{t}$

$n_{t} \quad$ Annual population rate growth

$\delta_{j, r, t} \quad$ Depreciation rate for capital for industry $\mathrm{j}$ in region $\mathrm{r}$ 